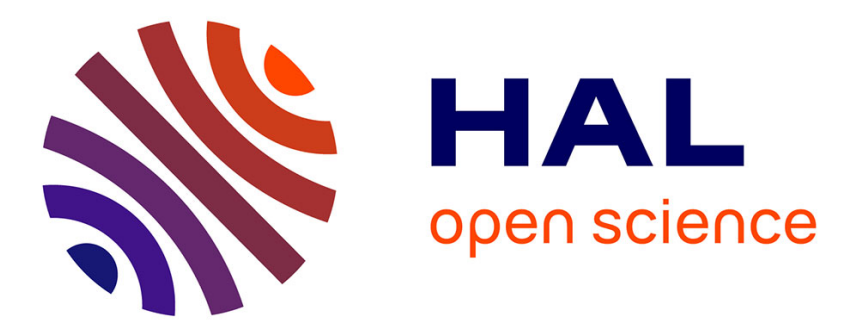

\title{
Evidence of the Current Collector Effect: Study of the SOFC Cathode Material Ca3Co4O9+ $\delta$
}

A. Rolle, V. Thoréton, Patrick Rozier, E. Capoen, O. Mentré, B. Boukamp, S.

Daviero-Minaud

\section{- To cite this version:}

A. Rolle, V. Thoréton, Patrick Rozier, E. Capoen, O. Mentré, et al.. Evidence of the Current Collector Effect: Study of the SOFC Cathode Material Ca3Co4O9+ $\delta$. Fuel Cells, 2012, 12 (2), pp.288-301. 10.1002/fuce.201100084 . hal-02069357

\section{HAL Id: hal-02069357 https://hal.science/hal-02069357}

Submitted on 22 Oct 2019

HAL is a multi-disciplinary open access archive for the deposit and dissemination of scientific research documents, whether they are published or not. The documents may come from teaching and research institutions in France or abroad, or from public or private research centers.
L'archive ouverte pluridisciplinaire HAL, est destinée au dépôt et à la diffusion de documents scientifiques de niveau recherche, publiés ou non, émanant des établissements d'enseignement et de recherche français ou étrangers, des laboratoires publics ou privés. 


\section{OATAO \\ Open Archive Toulouse Archive Ouverte}

\section{Open Archive Toulouse Archive Ouverte (OATAO)}

OATAO is an open access repository that collects the work of Toulouse researchers and makes it freely available over the web where possible

This is an author's version published in: http://oatao.univ-toulouse.fr/24433

Official URL: https://doi.org/10.1002/fuce.201100084

\section{To cite this version:}

Rolle, Aurélie and Thoréton, Vincent and Rozier, Patrick Edouard and Mentré, Olivier and Boukamp, Bernard and Daviero-Minaud, Sylvie Evidence of the Current Collector Effect: Study of the SOFC Cathode Material Ca3Co4O9+ $\delta$. (2012) Fuel Cells, 12 (2). 288-301. ISSN 1615-6846

Any correspondence concerning this service should be sent to the repository administrator: tech-oatao@listes-diff.inp-toulouse.fr 


\title{
Evidence of the Current Collector Effect: Study of the SOFC Cathode Material $\mathrm{Ca}_{3} \mathrm{CO}_{4} \mathrm{O}_{9+\delta} \mathrm{\Lambda}$
}

\author{
A. Rolle ${ }^{1 *}$, V. Thoréton ', P. Rozier ${ }^{2}$, E. Capoen ', O. Mentré ', B. Boukamp ${ }^{3}$, \\ S. Daviero-Minaud ${ }^{1}$ \\ 1 Univ. Lille Nord de France F-59000 Lille, CNRS UMR 8181-Unité de Catalyse et de Chimie du Solide-UCCS, ENSC, USTL bat C7 \\ avenue Dimitri Mendeleïev, BP 90 108, F-59652 Villeneuve d'Ascq cedex, France \\ 2 Centre d'Elaboration de Matériaux et d'Etudes Structurales, UPR CNRS 801 1, 29, rue Jeanne Marvig, BP 94 347, 31055 Toulouse \\ Cedex 4, France \\ 3 Faculty of Science \& Technology \& MESA ${ }^{+}$, Institute for Nanotechnology, University of Twente, P. O. Box 217,7500 AE Enschede, \\ The Netherlands
}

\begin{abstract}
In the study of the performance of solid oxide fuel cell (SOFC) electrodes, the possible influence of the applied current collector is often not mentioned or recognized. In this article, as part of an optimization study of the potentially attractive $\mathrm{Ca}_{3} \mathrm{Co}_{4} \mathrm{O}_{9+\delta}$ cathode material (Ca349), special attention is paid to the choice of current collector. The influence of both gold and platinum paste or grid current collectors on pure and composite (Ca349 + $30 \mathrm{wt}$.\% Gd-doped ceria) is studied, using electrochemical impedance spectroscopy (EIS). Although, platinum is catalytically active in the oxygen reduction reaction and then is often considered as current collector for SOFC cathodes, in combination with Ca349 cathodes, additional low frequency dispersion is observed, leading to a larger polarization resistance than
\end{abstract}

\section{Introduction}

In a solid oxide fuel cell (SOFC), the fundamental part of the cathode model is the oxygen reduction pathway. The mechanisms involved at the cathode at the triple phase boundary, where the oxygen reduction reaction occurs, are quite complex and are often modeled using multi-step mechanisms. They imply interactions, which can take place on the surface, but also in the whole thickness of the cathode layer. The steps to consider are oxygen diffusion, oxygen adsorp-

- Paper presented at the "Fundamentals and Developments of Fuel Cells-Conference 2011", January 19-21, 2011, Grenoble, France. found in the case of gold current collectors. A subsequent experiment revealed that $\mathrm{Pt}$ reacts with $\mathrm{Ca} 349$, forming undesirable phases: $\mathrm{CaPt}_{2} \mathrm{O}_{4}, \mathrm{Ca}_{4} \mathrm{PtO}_{6}, \mathrm{Ca}_{3} \mathrm{Co}_{2} \mathrm{O}_{6}$, and $\mathrm{Co}_{3} \mathrm{O}_{4}$. The impedance spectra were analyzed with $\mathrm{ZView}$ 3.3a and with $\mathrm{EqCwin}$ v1.2. One series equivalent circuit was deduced using ZView, whereas, two possible equivalent circuits (series and nested), leading to the same quality of fits, were evidenced in EqCwin. The circuits are closely related to interactions of the current collector and layer thickness effects of the cathodes.

Keywords: $\mathrm{Ca}_{3} \mathrm{Co}_{4} \mathrm{O}_{9+\delta}$, Cathode, Current Collection, Electrochemical Impedance Spectroscopy, Screen Printing, Solid Oxide Fuel Cell

tion/dissociation, charge transfer, and diffusion of ionic species [1]. They involve specific requirements for the considered materials in terms of microstructure, porosity, electrocatalytic properties, electronic/oxide ion conduction, and electrochemical properties. The cathode composition and morphology plays the main role. But one must keep in mind that the current collector can also interfere with the oxygen reduction reaction, especially if platinum is used. Indeed, its excellent catalytic properties toward this reaction justified its use as cathode in the first SOFCs developments [1-3].

$\left.{ }^{*}\right]$ Corresponding author, aurelie.rolle@ensc-lille.fr 
Within the framework of the study of cathodes for SOFCs, electrochemical impedance spectroscopy (EIS) is a method of choice to describe the electrochemical properties. However, drastic effects can be evidenced in the cathode electrochemical response according to the measurement conditions and more precisely the collector choice. In many studies using EIS to characterize the cathode properties, either the choice of current collector is not justified, or the type of current collector is not always specified. Generally platinum paste is used as current collector in the characterization of SOFCs' cathodes. We have recently pointed out as part of an optimization study of $\mathrm{Ca}_{3} \mathrm{Co}_{4} \mathrm{O}_{9+\delta}$ (Ca349, a potential cathode material $[4,5])$, that particular attention should be paid on the choice of the current collector.

$\mathrm{Ca}_{3} \mathrm{Co}_{4} \mathrm{O}_{9+\delta}$, a thermoelectric material, is expected to have two-dimensional ionic conduction due to oxygen vacancies associated with the mixed valence of cobalt in 2D-rock salt subunits. It is also a good electronic conductor $\left(\sigma=100 \mathrm{~S} \mathrm{~cm}^{-1}\right.$ at $\left.700{ }^{\circ} \mathrm{C}\right)$. It shows no reactivity with the gadolinium doped ceria standard electrolyte (CGO) and possesses a thermal expansion coefficient of $9-10 \times 10^{-6} \mathrm{~K}^{-1}$, which makes it compatible with CGO [2].

In the article, all the abbreviations considered, the cells characteristics and the equivalent circuit symbols are provided in the Supplementary Data Section (S1, S2, S3). In Figure 1 , the recently published results on Ca349 are summarized $[4,5]$. The same description of samples as in ref. [5] will be used in this paper. The sample designations are described in more details in the Supplementary Data Section (S2). From these results, one trend has been observed: the polarization resistance is lower for Ca349/CGO composites than for the single-phase electrodes. Moreover, the lowest polarization resistance is obtained for the thicker layers. The lowest polarization resistance is currently reported in ref. [4] for the 70 wt.\% Ca349-30 wt.\% CGO composite cathode: approximately $1 \Omega \mathrm{cm}^{-2}$ at $700{ }^{\circ} \mathrm{C}$ measured on thick electrolyte support.
From the impedance diagrams presented in Figure 1, it is obvious that the use of platinum as current collector raises the question of a possible current collector effect.

With the aim to highlight the importance of the choice and on the effect of the current collector, this article focuses on the influence of several current collectors (gold grid, gold paste, platinum grid, and platinum paste) on the electrochemical response of the Ca349 cathodes. The impedance data has been analyzed with ZView 3.3a [6] and with EqCwin v1.2 (Windows version of Equivalent Circuit [7-9]), in which more detailed equivalent circuit models have been extracted.

\section{Experimental}

The synthesis of the Ca349 powder, the Ca349-based inks and the preparation of the pellets for the microstructural and electrochemical characterizations were performed as presented in ref. [5]. Cathode layers were screen-printed using a DEK 248 screen-printer. Depending on the type of sample/ current collector assembly thermal treatments at 700, 800, or $900{ }^{\circ} \mathrm{C}$ were applied. More information on each cell is provided in the Table S2 given in the Supplementary Data Section. For current collector deposition, Au paste (Ferro couleurs, France SA), mixed with DH 43 (dmc ${ }^{2}$ Limoges, France) was deposited by hand painting on the cell, followed by a thermal treatment at $650{ }^{\circ} \mathrm{C}$ in order to decompose the organic part. The $\mathrm{Pt}$ paste $\left(\mathrm{dmc}^{2}\right.$ Limoges) was deposited similarly and treated at $800{ }^{\circ} \mathrm{C}$. EDS analysis has revealed the purity of the gold and platinum paste.

Microstructural characterizations were performed by scanning electron microscopy using a Hitachi S3400N SEM. X-ray diffraction was performed on powders and on deposited layers using a D8 Advance A25 Bruker with a Position Sensitive Detector Lynxeye or using a D8 Bruker AXS diffractometer $(\mathrm{CuK} a=1.54 \AA)$. In order to determine the oxygen mobility in Ca349, permeation measurements were carried out, using the same protocol as described in ref. [10], on

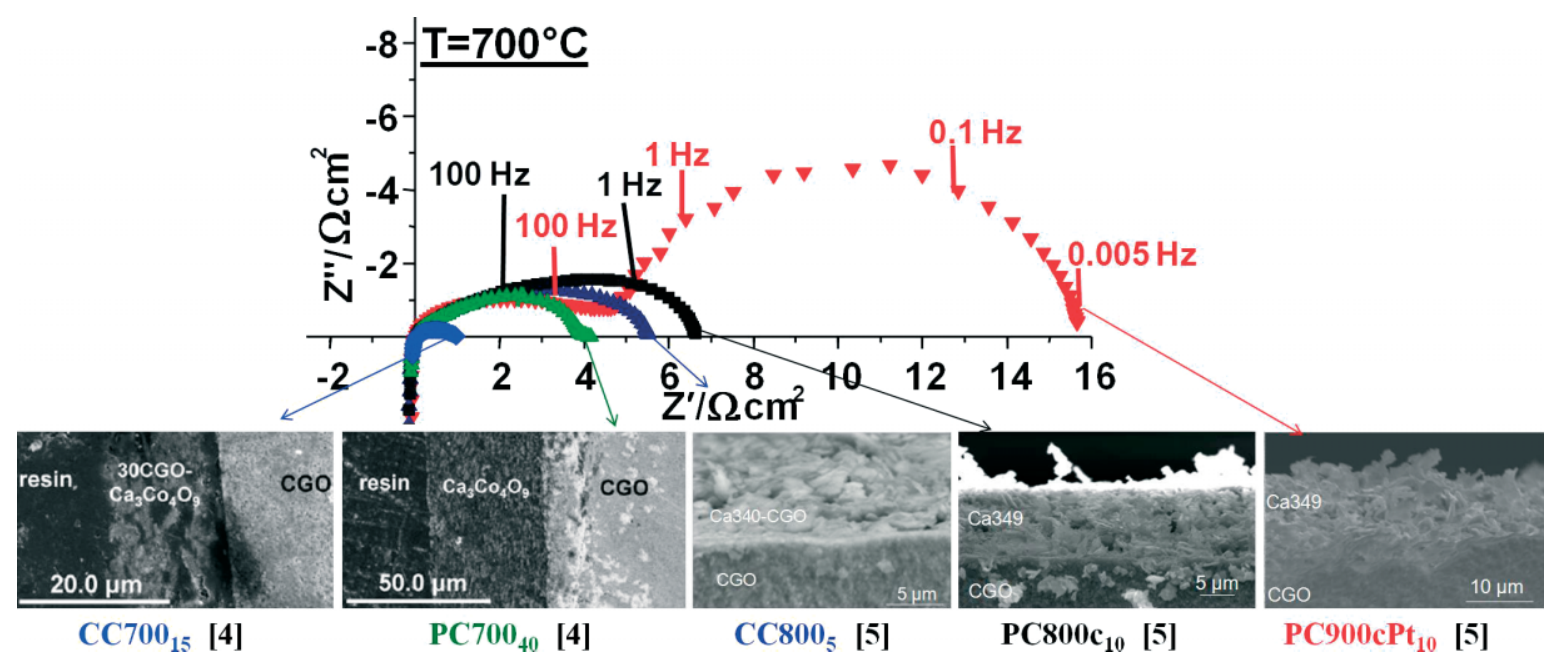

Fig. 1 Recently published data on Ca349 [4, 5]. 
dense pellets (97\%) obtained by spark plasma sintering (SPS), performed in the PNF2 Platform $\left(T_{\max }=850{ }^{\circ} \mathrm{C}\right.$ and $P_{\text {max }}=50 \mathrm{MPa}$, densification starting at $600{ }^{\circ} \mathrm{C}$ until $850{ }^{\circ} \mathrm{C}$ ) (Toulouse, France).

Pellets have been checked by XRD. Impedance measurements were performed on symmetrical cells, cathode/electrolyte/cathode, using a SI 1260 Solartron FRA, during a heating-cooling sequence. An optimized signal amplitude of $50 \mathrm{mV}$ (pure Ca349) and $70 \mathrm{mV}$ (composite Ca349) were imposed, with respect to the linearity of the electrical response. Four types of current collectors were applied: gold grid, platinum grid, gold paste, and platinum paste. The data collection procedure was identical to the one reported in ref. [5]. At each temperature, the thermal and time stability were checked. The data were collected when the change in the polarization resistance was less than $5 \%$. After a temperature change, measurements were performed as function of time. It was found that stability is reached within $2 \mathrm{~h}$ after each temperature change. The impedance data were analyzed using two different software packages: ZView 3.3a [6] and Equivalent Circuit 1.2. (Windows version EqCwin) [7-9]. For use of the latter programme, the stability and validity of the considered data was checked using the Kramers-Kronig (KK) test for Windows, version 1.01 [11, 12].

\section{Results and Discussion}

\subsection{Ionic Conduction Properties}

Ca349 is known for its good electrical conductivity property, which is reported to be higher than $100 \mathrm{~S} \mathrm{~cm}^{-1}$ over the 20-800 ${ }^{\circ} \mathrm{C}$ temperature range $[4,13]$. However, the ionic conduction of this phase has never been checked before. For that purpose, permeation measurements were performed on $0.5 \mathrm{~mm}$ thick and $15 \mathrm{~mm}$ diameter SPS-dense pellets (relative density $>97 \%$ ) of the pure Ca349 material. Both faces of the pellets were polished with up to 2,400 grid and the experiments were carried out between 580 and $650{ }^{\circ} \mathrm{C}$. The oxygen flux is deduced from the $\Delta p \mathrm{O}_{2}$ variation at the permeate side. The oxygen permeation measurements revealed a significant oxygen flux even at low temperatures $\left(0.0014 \mu \mathrm{mol} \mathrm{cm} \mathrm{cm}^{-2} \mathrm{~s}^{-1}\right.$ at $600{ }^{\circ} \mathrm{C}$ ), which unquestionably proves the existence of oxygen-ion migration (Table 1). For information, the oxygen fluxes reported for $\mathrm{La}_{0.6} \mathrm{Sr}_{0.4} \mathrm{Co}_{0.8} \mathrm{Fe}_{0.2} \mathrm{O}_{3-\mathrm{d}}$ (LSCF) in the literature [14] are about $0.00562 \mu \mathrm{mol} \mathrm{cm}{ }^{-2} \mathrm{~s}^{-1}$ at $850{ }^{\circ} \mathrm{C}$, but one can notice, that the membrane thickness, $\mathrm{pO}_{2}$ gradients,

Table 1 Oxygen permeation measurements: comparison of Ca349 and LSCF.

\begin{tabular}{lll} 
Membrane & $\mathrm{Ca}_{3} \mathrm{Co}_{4} \mathrm{O}_{9+\delta}(\mathrm{Ca} 349)$ & $\begin{array}{l}\mathrm{La}_{0.6} \mathrm{Sr}_{0.4} \mathrm{Co}_{0.8} \mathrm{Fe}_{0.2} \mathrm{O}_{3} \text { (LSCF) } \\
{[13]}\end{array}$ \\
\hline Temperature $/{ }^{\circ} \mathrm{C}$ & $600-700$ & $850-1000$ \\
$J\left(\mathrm{O}_{2}\right) / \mu \mathrm{mol} \mathrm{cm}{ }^{-2} \mathrm{~s}^{-1}$ & $0.0014-0.0020$ & $0.00562-0.0316$ \\
$\mathrm{Thickness} / \mathrm{mm}$ & 0.50 & $0.55-0.98$ \\
$p^{\prime} \mathrm{O}_{2} /$ atm & 1.00 & 0.21 \\
& $3 \times 10^{-6}$ & $1 \times 10^{-3}$
\end{tabular}

and temperature range are different, making a direct comparison difficult. Nevertheless the flux measured for Ca349 is about the same order, but measured at significantly lower temperatures. However, after the permeation measurements, a surfacial passivation of $\mathrm{Ca} 349$ into $\mathrm{CaO}$ and $\mathrm{CoO}$, was observed due to the long-exposure time of the pellet under $\mathrm{Ar}$ atmosphere at $700{ }^{\circ} \mathrm{C}$. This experiment confirms Ca349 as a mixed oxide ion and electronic conductor and shows its potentiality as cathode material in SOFC applications.

\subsection{Current Collector Effect}

\subsubsection{Gold Paste Versus Gold Grid}

The same composite sample $\mathrm{CC} 800_{20}$ characterized in ref. [5] with gold grid only $\left(\mathrm{CC} \mathrm{CO0}{ }_{20}\right)$ was also studied here with gold paste $\left(\mathrm{CC} 800 \mathrm{Au}_{20}\right)$ as current collector. The comparison between these two kinds of current collectors revealed that the electrochemical properties are the same, independent of the type of gold current collector. For example, the comparison of the impedance spectra recorded at $700{ }^{\circ} \mathrm{C}$ is shown in Figure 2(a). A random shift of the series resistance is observed on the impedance spectra, reported Figure 2, which might be due to the global measuring set-up.

For this $20 \mu \mathrm{m}$ thick cathode layer, polarization resistances of 1.39 and $1.41 \Omega \mathrm{cm}^{2}$ were obtained for the gold grid and the gold paste, respectively. The cross-section of the cell after EIS measurements is presented in Figure 3(a). The gold layer is about $5 \mu \mathrm{m}$ thick. After the EIS measurements no additional phase could be observed in the X-ray diffraction pattern [Figure 4(a)]. The reactivity test between Ca349 and Au at $700{ }^{\circ} \mathrm{C}$ for $72 \mathrm{~h}$ also revealed no interaction between these two phases, as can be noticed in the X-ray diffraction pattern of Figure 4(b). The impedance plots consist of a single depressed semicircle which does not change noticeably with time [Figure S4 in Supplementary Data Section]. From these results, it can be inferred that the impedance response represents the properties of Ca349 only.

\subsubsection{Platinum Paste Versus Gold Grid}

A comparison of the electrochemical properties of identical composite $\mathrm{CC} 800_{5}$ cathodes with either platinum paste or gold grid as current collector is presented in Figure 2(b). These results have been reproduced from ref. [5]. Activation energies determined for the case of gold grid and platinum paste current collectors (1.15 and $1.52 \mathrm{eV}$, respectively), reveal that, when platinum paste is used as current collector, the cathode behavior is more complex and the ASR values are less favorable [5]. Special attention is paid to the impedance properties at $700{ }^{\circ} \mathrm{C}$. At this temperature, polarization resistances of about 5.6 and $12.9 \Omega \mathrm{cm}^{2}$ are obtained, respectively, for gold grid and platinum paste used as current collector [5] with the same sample. Even if the platinum layer is quite thin [about less than $1 \mu \mathrm{m}$, Figure 3(b)], a clear growing contribution is observable in the impedance plot at low frequency, as compared to the gold grid collector case. This 
(a)

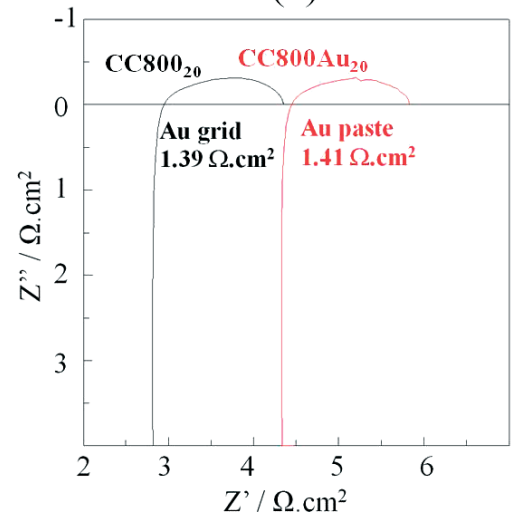

(b)

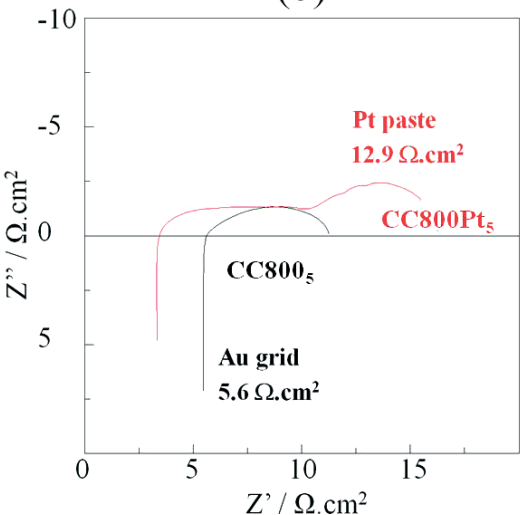

(c)

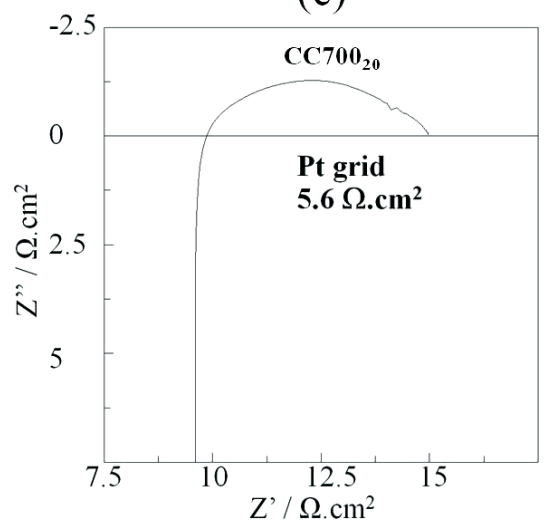

Fig. 2 Effect of the current collector on the electrochemical property: (a) gold paste-gold grid, (b) platinum paste-gold grid, and (c) platinum grid. Data are reported at $700{ }^{\circ} \mathrm{C}$.

(a)

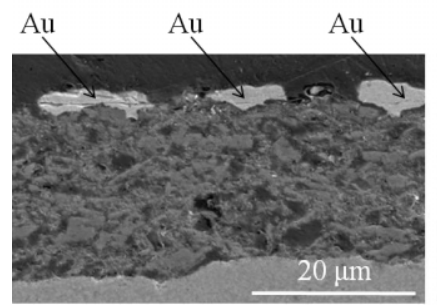

(b)

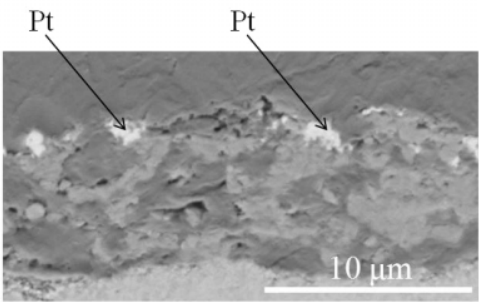

(c)

$\mathrm{Pt}$

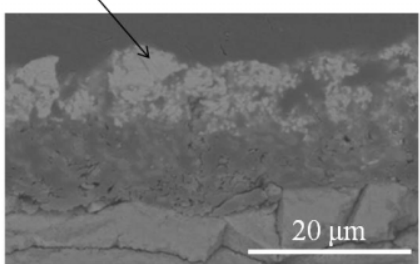

(d)

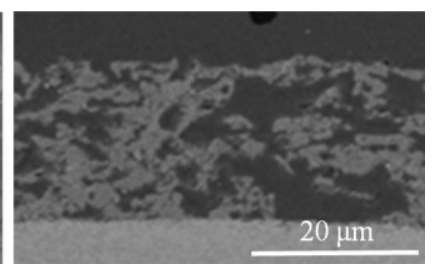

Fig. $3 \mathrm{SEM}$ cross-section of (a) $\mathrm{CC} 800 \mathrm{Au}_{20}$, (b) $\mathrm{CC} 800 \mathrm{Pt}_{5}$, (c) $\mathrm{PC} 900 \mathrm{cPt}_{10}$, and (d) $\mathrm{CC} \mathrm{CO}_{20}$ after ElS characterization.
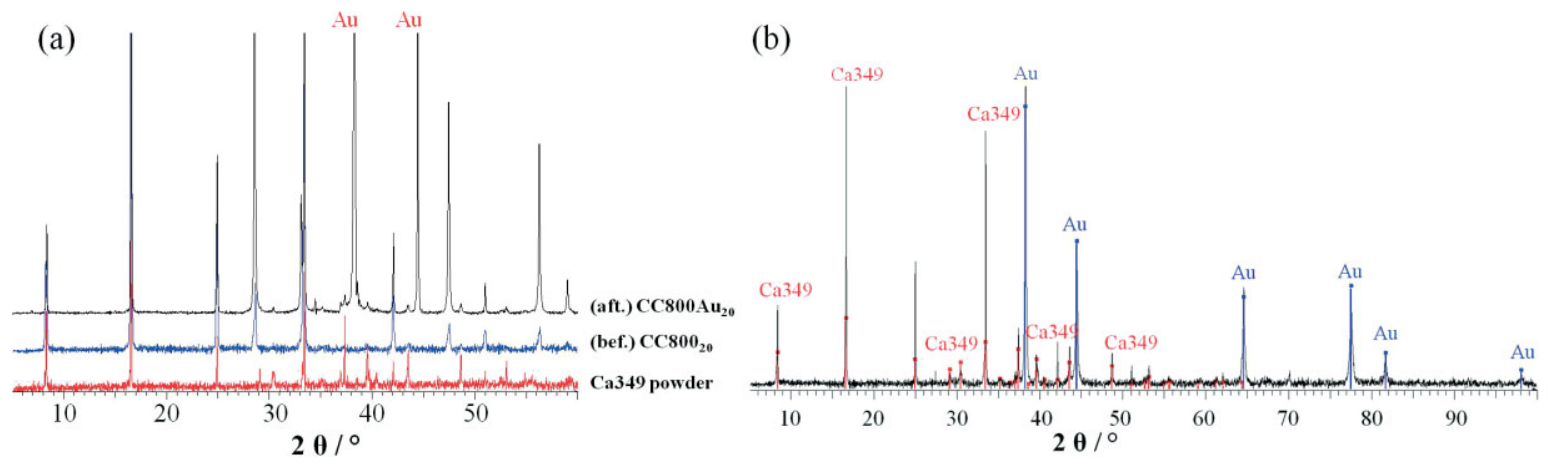

Fig. 4 (a) Comparison of the X-ray diffractograms of Ca349 powder, $\mathrm{CC} 800_{20}$, and $\mathrm{CC} 800 \mathrm{Au}_{20}$ before gold painting (bef.) and after EIS measurements (aft.). (b) Reactivity test of Ca349 and gold at $700^{\circ} \mathrm{C}$ for $72 \mathrm{~h}$.

growing contribution is observed in the impedance plot of all the samples (pure as well as composite ones) measured with a Pt-paste current collector, independently of the platinum thickness [5]. X-ray diffraction was performed on the $\mathrm{CC} 800_{5}$ pellets after EIS characterizations, in order to get a better understanding of the difference in behavior as observed between the gold grid and the platinum paste current collectors. For the Pt-paste, the $\mathrm{X}$-ray analysis revealed the formation of undesirable phases [Figure 5(a)]. To confirm this result, a reactivity test was then performed on pellets prepared by mixing Ca349 and Pt powder and firing at $700{ }^{\circ} \mathrm{C}$ for $72 \mathrm{~h}$. Additional peaks corresponding to phases, such as $\mathrm{CaPt}_{2} \mathrm{O}_{4}, \mathrm{Ca}_{4} \mathrm{PtO}_{6}, \mathrm{Ca}_{3} \mathrm{Co}_{2} \mathrm{O}_{6}$, and $\mathrm{Co}_{3} \mathrm{O}_{4}$ are highlighted
[Figure 5(b and c)], confirming a chemical reaction between Ca349 and Pt. A study, whose results have never been published before [15], has revealed that the $\mathrm{Ca}_{3} \mathrm{Co}_{2} \mathrm{O}_{6}$ phase, which consists of a one-dimensional structure, has quite poor conducting properties and cathode behavior, as compared to Ca349, with a polarization resistance of $96.2 \Omega \mathrm{cm}^{-1}$ at $700{ }^{\circ} \mathrm{C}$ (Figure 6). The growing contribution observed in the impedance plot could thus be assigned to undesirable phases resulting from the reaction on the surface between Ca349 and the platinum paste. 
(a)

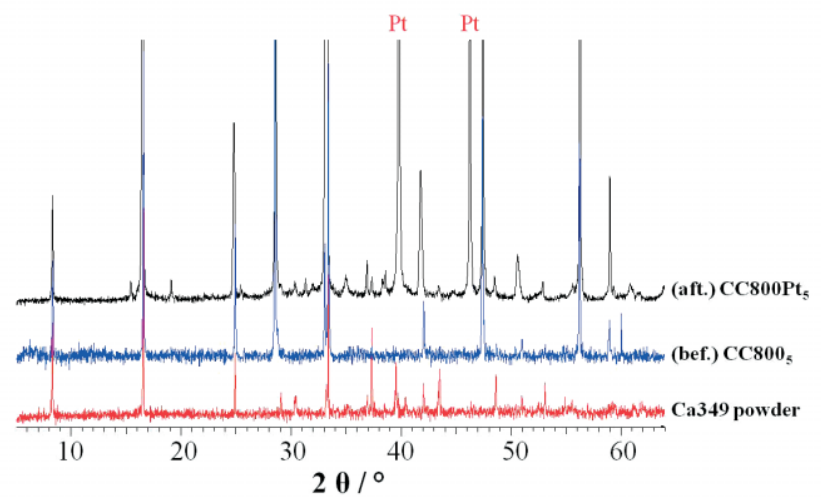

(b)

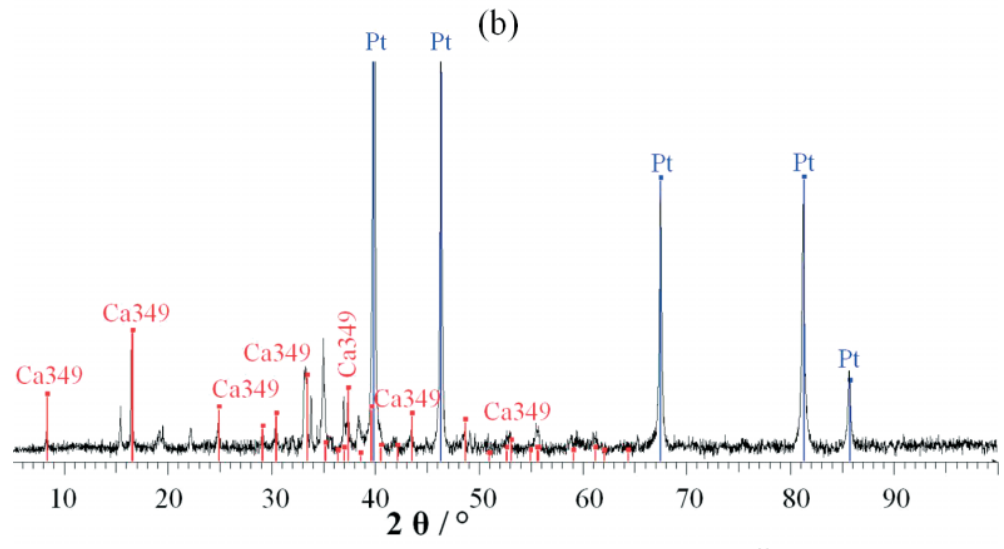

(c)

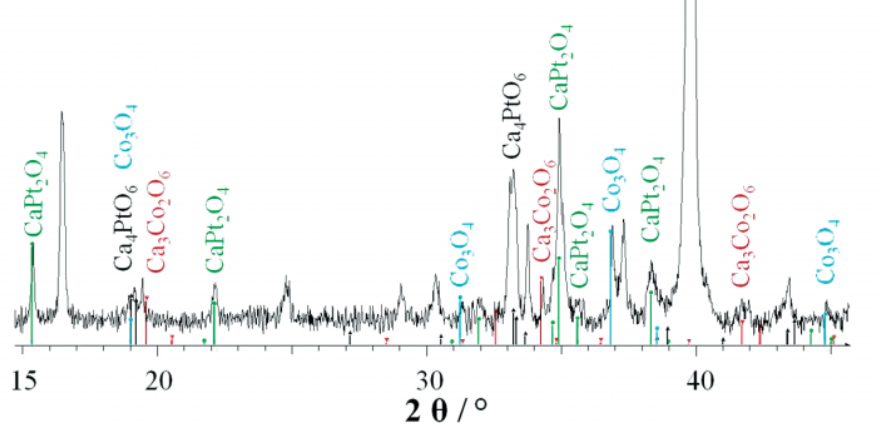

Fig. 5 (a) Comparison of the X-ray diffractograms of $\mathrm{Ca} 349$ powder, $\mathrm{CC} 80 \mathrm{O}_{5}$, and CC800 $8 \mathrm{Pt}_{5}$ before Pt painting (bef.) and after EIS measurements (aft.). (b and c) Reactivity test of $\mathrm{Ca} 349$ and platinum at $700{ }^{\circ} \mathrm{C}$ for $72 \mathrm{~h}$.

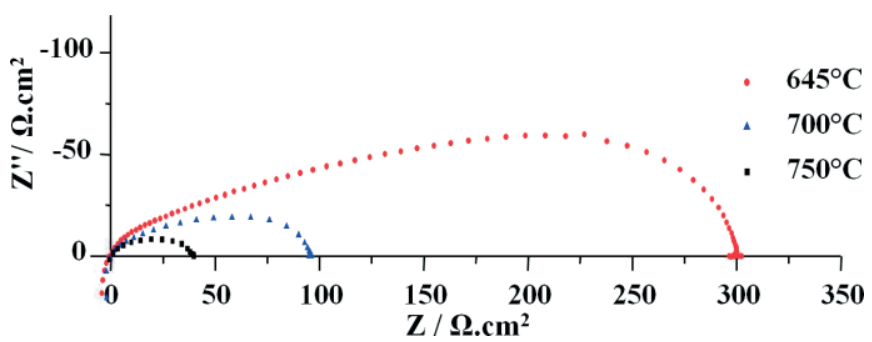

Fig. 6 Impedance spectroscopy plots of $\mathrm{Ca}_{3} \mathrm{Co}_{2} \mathrm{O}_{6}$ in the temperature range 500$700^{\circ} \mathrm{C}$.

\subsubsection{Platinum Grid}

On sample $\mathrm{CC} 700_{20}$, of which the layer microstructure is presented in Figure 3(d), a platinum grid collector was tested. In comparison with the gold grid case, a small deviation at the low frequency end of the depressed semicircle can be discerned [Figure 2(c)]. The low frequency semi-circle starts to appear. This trend is intermediate between the electrochemical behavior as observed using gold grid and platinum paste. Again this may be related to the Ca349/Pt reaction. X-ray diffraction performed after the impedance spectroscopy measurements confirms a beginning of reaction between Ca349 and the platinum grid leading to $\mathrm{Co}_{3} \mathrm{O}_{4}$, $\mathrm{CaPt}_{2} \mathrm{O}_{4}$, and $\mathrm{Ca}_{3} \mathrm{Co}_{2} \mathrm{O}_{6}$ formation, as indicated by additional peaks to those of the Ca349 and CGO phases (Figure 7).

\subsubsection{Fit Procedures}

\section{Evidence of the Ca349 Equivalent Circuit. Comparison of Z View Versus EqCWin}

We have first focussed on the pure compounds PC $800 c_{10}$, measured with a gold grid. In this article, two fitting softwares are considered and compared to analyze the same data set: Z View 3.3a [6] and EqCwin v1.2 [7-9]. Using EqCwin v1.2, the approach consists of first checking the data quality using the KK test for Windows, version 1.01 [11, 12]. This test, which should be performed directly after an impedance measurement, provides a check for the validity and stability of the data. The quality of the data can be observed in the residuals plot of the KK-test. The relative residuals, $\Delta_{\text {real }}$ and $\Delta_{\text {imag, }}$ are defined as [11]:

$$
\begin{gathered}
\Delta_{\text {real }}\left(\omega_{\mathrm{i}}\right)=\frac{Z_{\text {real }}\left(\omega_{\mathrm{i}}\right)-K K_{\text {real }}\left(\omega_{\mathrm{i}}\right)}{\left|Z\left(\omega_{\mathrm{i}}\right)\right|}, \\
\Delta_{\text {imag }}\left(\omega_{\mathrm{i}}\right)=\frac{Z_{\text {imag }}\left(\omega_{\mathrm{i}}\right)-\mathrm{KK}_{\text {imag }}\left(\omega_{\mathrm{i}}\right)}{\left|Z\left(\omega_{\mathrm{i}}\right)\right|}
\end{gathered}
$$

where $\operatorname{KK}\left(\omega_{\mathrm{i}}\right)$ is the Kramers-Kronig test function. Valid data should present a random distribution of the relative residuals around the $\log \left(\omega_{\mathrm{i}}\right)$ axis, representing basically the noise distribution of the data. A systematic deviation from the frequency axis indicates non-KK behavior, which can be caused by several factors. The most important reasons are a nonequilibrium state of the cell, for example, the system has not completely adjusted to the last temperature change or a change in the ambient composition. But it can also be caused by a strong non-linear transfer function, which is inherent to electrode responses when a too large perturbation voltage is used $[11,12]$. 


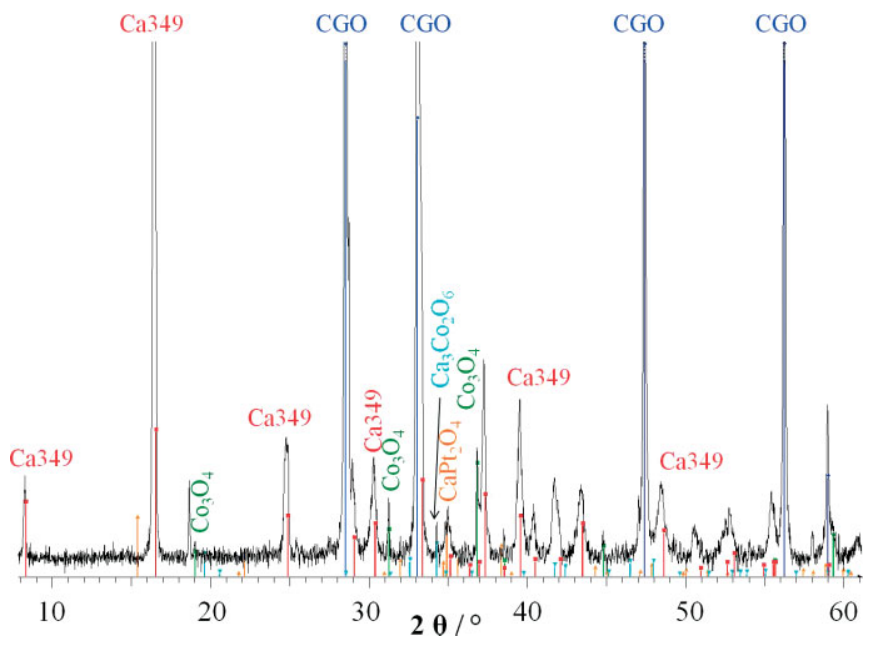

Fig. 7 X-ray diffractograms of $\mathrm{CC} \mathrm{CO}_{20}$ after EIS measurements.

In general, for a good CNLS-fit the residuals distribution should be similar in shape as observed for the KK-test [12]. Since the KK-test also indicates the frequency limits that will allow an optimal fit procedure, a significant difference between the residuals plot for the KK-test and the final CNLS-analysis can indicate that the data contains either an additional contribution or that the used equivalent circuit is not appropriate.

Whereas, ZView 3.3a uses a (semi) automatic search for the equivalent circuit with the "best fit" to the data set, EqCwin provides a partial fit and subtraction procedure with which a possible equivalent circuit is built and starting values for the fit parameters are obtained. These are subsequently used for a final overall CNLS-fit of the complete data set. The clear advantage of this procedure is that minor contributions, that are not obvious from visual inspection of the data, are readily detected [7, 12]. Final comparison of the residuals distributions between the KK-test and the CNLS-fit can confirm the viability of the derived equivalent circuit to model the data set. In Figure 8 ( $a$ and b) the KK-tests indicate for the data of sample PC $800 c_{10}$ a perfect KK behavior.

Two possible equivalent circuits can be derived using EqCwin: a series circuit and a nested circuit. A very good match between data set and model function can be observed, as demonstrated in Figure 8(c and d), where the final CLNSfit of the data measured at $700{ }^{\circ} \mathrm{C}$ is presented. The corresponding circuit element values and error estimates are presented in Table 2 . The nested arrangement assumes a double layer capacitance between the electrode and the electrolyte, which results in a parallel capacitance to the electrode response. Both circuits have been checked for various temperatures, various compositions (composite $70 \%$ $\mathrm{Ca}_{3} \mathrm{Co}_{4} \mathrm{O}_{9}-30 \% \mathrm{CGO}$, pure $\left.\mathrm{Ca}_{3} \mathrm{Co}_{4} \mathrm{O}_{9}\right)$, various layer thicknesses, various current collectors (gold grid, gold paste, and platinum paste), various oxygen partial pressure, and leads to good fits of similar quality. The extracted circuits correspond to the minimal number of contributions necessary for a good fit quality. Adding an extra circuit does not automati- cally improve the fit. Inappropriate additions to the EqCwin will generally result in a shift of the element parameters to either zero or infinity during the fit procedure. Particular focus should be paid on the errors obtained in ZView and EqCwin which are not calculated in the same way, then, the obtained values cannot be compared. The errors in ZView are based on the number of experimental points considered, whereas, the error estimates in EqCwin are based on the assumption that the residual errors can be assumed to represent the parent distribution [8, 12]. This last point requires that the residuals are randomly distributed around the $\log (\omega)$ axis. A systematic deviation from 0 around the $\log (\omega)$ axis invalidates the calculation of the error estimates.

Here, as example, we present Figure 8 and Table 2 the results concerning only the impedances data measured at $700{ }^{\circ} \mathrm{C}$ under air atmosphere. The specific resistances associated to a frequency range are of the same order of magnitude, whatever the type of circuit, series or nested. That means, with the chosen notation: $\left(R_{1}\right)_{\text {series }}=\left(R_{1}\right)_{\text {nested; }}\left(R_{2}\right)_{\text {series }}=\left(R_{4}\right)_{\text {nested }}$; $\left(R_{3}\right)_{\text {series }}=\left(R_{2}\right)_{\text {nested}} ; \quad\left(R_{4}\right)_{\text {series }}=\left(R_{3}\right)_{\text {nested }} ;$ and $\quad\left(R_{5}\right)_{\text {series }}=$ $\left(R_{5}\right)_{\text {nested. }}$ Both circuits involve the same number of parameters. The series circuit imply successive steps in the cathode reaction, whereas, the nested one, consider one step occurring at the same time as the other ones.

Considering the ZView 3.3a program, an equivalent circuit consisting of a series association of a finite Warburg $(W)$ and (R/ /CPE) elements is extracted, corroborating the results of previous studies [4]. A comparison between the fitted model and the experimental data is provided in the Supplementary Section S5. The corresponding circuit elements are given Table 2.

The two fit procedures, ZView and EqCwin, lead in the case of PC $800 c_{10}$ to quite different model circuits. But for a comparison purpose, the series circuits extracted from EqCwin has been applied in ZView (Supplementary data S6). However, a small improvement of the fit is observed because of the higher number of fitted elements. But the additional part of the circuit is associated to a too big error to be considered. By constructing progressively the circuit, using various data in function of the temperature, the first proposed ZView circuit with the corresponding errors is more justified. Moreover, if the nested circuit is applied in ZView, the fit is not stable (Supplementary data S6).

As the series and the nested circuits extracted from EqCwin lead to the same fit quality and as the application of the nested circuit in ZView is unstable, for an easier comparison between the two softwares, the series circuit only will be considered for the rest of the study. Knowing that CCO is a mixed ionic-electronic conductor, we can expect several intermediate mechanisms, involving the surface reaction, the electrode-electrolyte interface diffusion, and the diffusion in the cathode itself. They cannot be clearly identified using the elementary ZView circuit with two (even three) contributions, which provide a too rough description. In that case, the subtraction technique developed in EqCwin leads to a more complex circuit consisting of four contributions corresponding to the best fit quality with the minimal number of contri- 
(a)

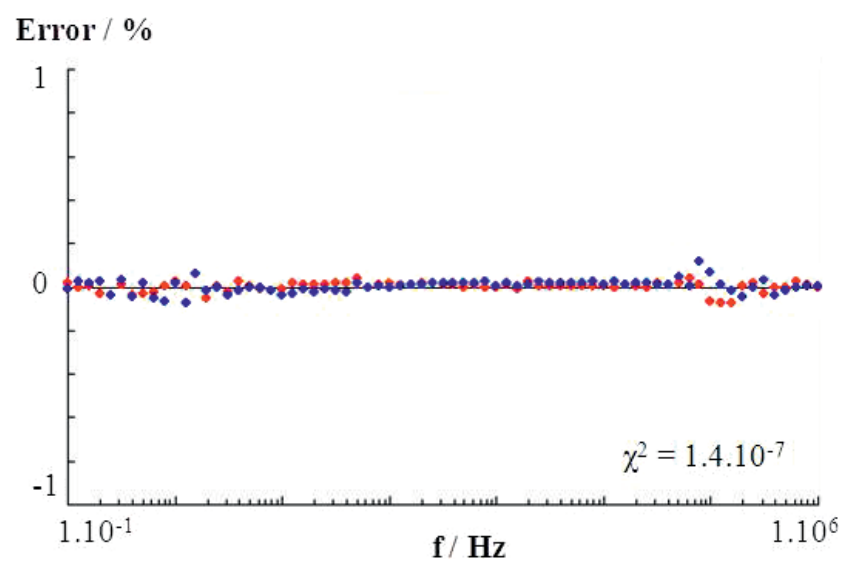

(b)

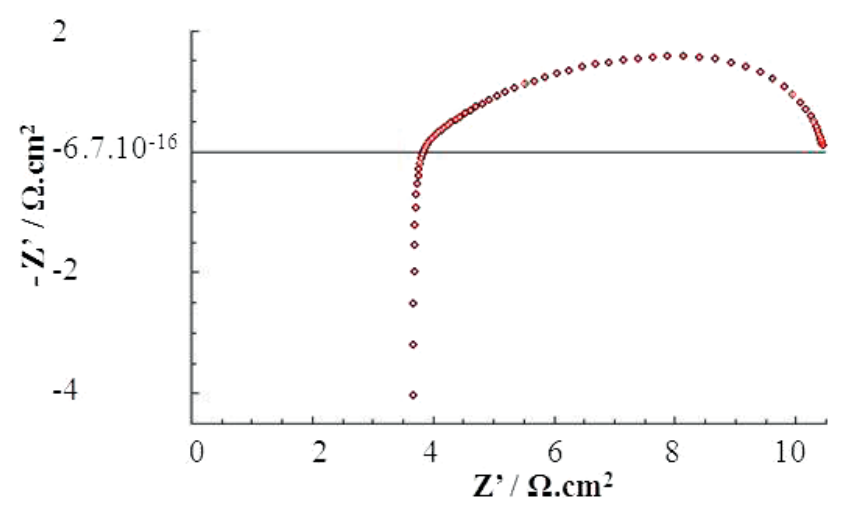

(c)
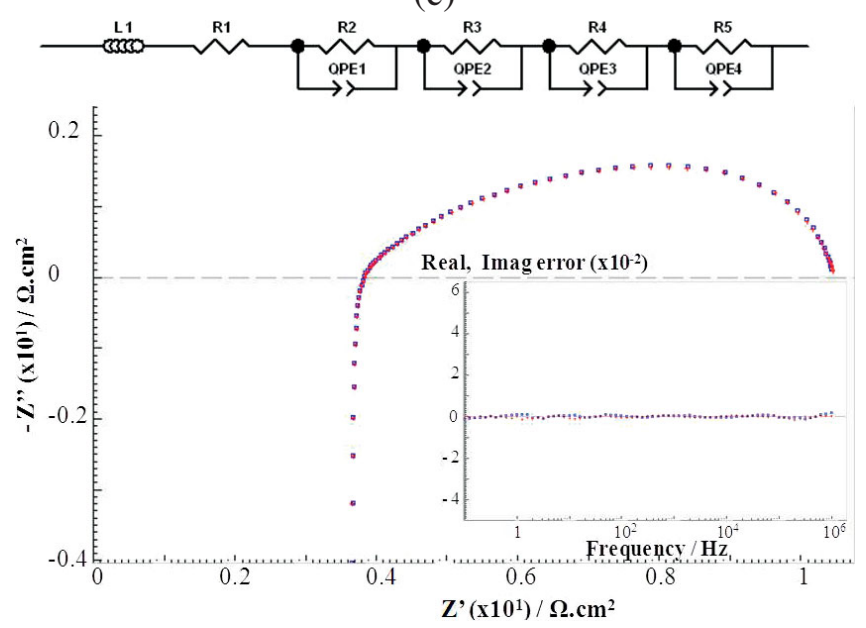

(d)

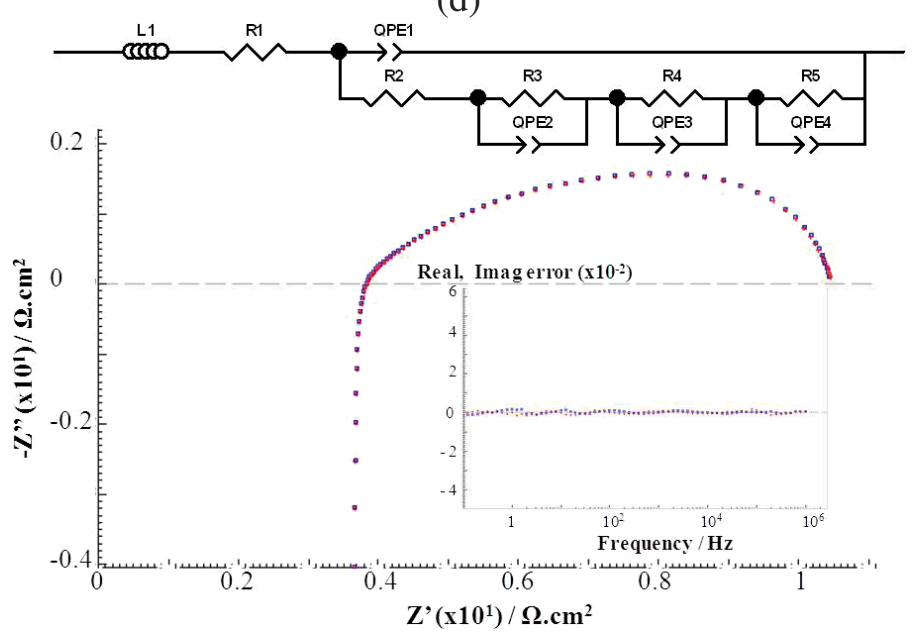

Fig. 8 (a) KK tests for $\mathrm{PC} 800 \mathrm{c}_{10}$. The red plot corresponds to the real part differences and the blue plot to the imaginary part differences. (b) Ideal fits possible to get using the considered data set for $\mathrm{PC} 800 \mathrm{c}_{10}$. Fit is represented in red and impedance data in black. (c and d) Comparison of the experimental and fitted impedance plots of $\mathrm{PC} 800 \mathrm{c}_{10}$, using the subtraction procedure on Equivalent Circuit 1.2 soffware, considering the series and the nested equivalent circuit, respectively. The corresponding residual plots are reported in insert. Fit are represented in red cross and impedance data in blue square.

Table 2 PC800 $c_{10}$ : comparison of the fitted circuit elements using ZView 3.3a and Equivalent Circuit 1.2 softwares.

\begin{tabular}{|c|c|c|c|}
\hline \multicolumn{2}{|l|}{ ZView 3.3a } & \multicolumn{2}{|l|}{ EqCwin 1.2} \\
\hline Circuit description & Circuit description & Circuit description & Circuit description \\
\hline$R_{1} L_{1} W_{\mathrm{s}}\left(R_{2} / / \mathrm{CPE}_{1}\right)[5]$ & $R_{1} L_{1} W_{\mathrm{s}}\left(R_{2} / / \mathrm{CPE}_{1}\right)\left(R_{3} / / \mathrm{CPE}_{2}\right)$ & $L_{1} R_{1}\left(R_{2} Q_{1}\right)\left(R_{3} Q_{2}\right)\left(R_{4} Q_{3}\right)\left(R_{5} Q_{4}\right)$ & $L_{1} R_{1}\left(Q_{1}\left[R_{2}\left(R_{3} Q_{2}\right)\left(R_{4} Q_{3}\right)\left(R_{5} Q_{4}\right)\right]\right)$ \\
\hline$t=696{ }^{\circ} \mathrm{C}$ & $t=696^{\circ} \mathrm{C}$ & $t=696^{\circ} \mathrm{C}$ & $t=696^{\circ} \mathrm{C}$ \\
\hline Circuit elements & Circuit elements & Circuit elements & Circuit elements \\
\hline$R_{1}=3,557 \Omega(0.1 \%)$ & $R_{1}=3,557 \Omega(0.1 \%)$ & $L_{1}=6.5 \times 10^{-7}$ Henri $(0.1 \%)$ & $L_{1}=6.5 \times 10^{-7}$ Henri $(0.1 \%)$ \\
\hline$L_{1}=6.5 \times 10^{-7}$ Henri $(0.1 \%)$ & $L_{1}=6.5 \times 10^{-7}$ Henri $(0.1 \%)$ & $R_{1}=3.6 \Omega(0.4 \%)$ & $R_{1}=3.7 \Omega(0.2 \%)$ \\
\hline$W_{\mathrm{s}}-R=3.64(2 \%)$ & $W_{\mathrm{s}}-R=2.10(3 \%)$ & $R_{2}=1.7 \Omega(35.2 \%)$ & $Q_{1}-Y_{0}=2.2 \times 10^{-4}$ mho $(104.8 \%)$ \\
\hline$W_{\mathrm{s}}-T=0.0046(5 \%)$ & $W_{\mathrm{s}}-T=0.0018(5 \%)$ & $Q_{1}-Y_{0}=2.3 \times 10^{-2}$ mho $(30.3 \%)$ & $Q_{1}-n=7.4 \times 10^{-1}(10.3 \%)$ \\
\hline \multirow[t]{2}{*}{$W_{\mathrm{s}}-P=0.336(0.5 \%)$} & $W_{\mathrm{s}}-P=0.309(1 \%)$ & $Q_{1}-n=9.3 \times 10^{-1}(4.1 \%)$ & $R_{2}=3.1 \times 10^{-1} \Omega(29.6 \%)$ \\
\hline & & $R_{3}=6.2 \Omega(79.2 \%)$ & $R_{3}=2.6 \Omega(40.0 \%)$ \\
\hline$R_{2}=3.33 \Omega(2 \%)$ & $R_{2}=2.9 \Omega(8 \%)$ & $Q_{2}-Y_{0}=2.3 \times 10^{-2}$ mho (45.4\%) & $Q_{2}-Y_{0}=6.9 \times 10^{-3}$ mho $(18.9 \%)$ \\
\hline $\mathrm{CPE}_{1}-\mathrm{T}=0.0124(2 \%)$ & $\mathrm{CPE}_{1}-\mathrm{T}=0.0071(7 \%)$ & $Q_{2}-n=4.1 \times 10^{-1}(11.1 \%)$ & $Q_{2}-n=5.4 \times 10^{-1}(4.4 \%)$ \\
\hline \multirow[t]{6}{*}{$\mathrm{CPE}_{1}-P=0.797(1 \%)$} & $\mathrm{CPE}_{1}-P=0.71(2 \%)$ & $R_{4}=2.6 \Omega(76.9 \%)$ & $R_{4}=2.2 \Omega(62.6 \%)$ \\
\hline & & $Q_{3}-Y_{0}=5.7 \times 10^{-3}$ mho $(17.6 \%)$ & $Q_{3}-Y_{0}=8.3 \times 10^{-3}$ mho $(9.1 \%)$ \\
\hline & $R_{3}=1.8 \Omega(11 \%)$ & $Q_{3}-n=6.0 \times 10^{-1}(12.3 \%)$ & $Q_{3}-n=7.4 \times 10^{-1}(14.5 \%)$ \\
\hline & $\mathrm{CPE}_{2}-T=0.021(7 \%)$ & $R_{5}=2.0 \Omega(105.0 \%)$ & $R_{5}=1.7 \Omega(25.8 \%)$ \\
\hline & $\mathrm{CPE}_{2}-P=0.91(2 \%)$ & $Q_{4}-Y_{0}=9.4 \times 10^{-3}$ mho $(18.3 \%)$ & $Q_{4}-Y_{0}=2.1 \times 10^{-2}$ mho $(19.0 \%)$ \\
\hline & & $Q_{4}-n=7.8 \times 10^{-1}(21.2 \%)$ & $Q_{4}-n=9.3 \times 10^{-1}(3.6 \%)$ \\
\hline$\chi^{2}=6.3 \times 10^{-5}$ & $\chi^{2}=6.3 \times 10^{-6}$ & $\chi^{2}=3.6 \times 10^{-7}$ & $\chi^{2}=5.5 \times 10^{-7}$ \\
\hline
\end{tabular}


butions, which may provide additional information on the cathode behavior.

To have a better understanding of the current collector and of the layer thickness, the same analysis approach will be applied on selected composite cathodes. We have focused on a cell with a composite Ca349 cathode, measured successively with a gold grid and with platinum paste (cathodes: $\mathrm{CC} 800_{5}$ and $\left.\mathrm{CC} 800 \mathrm{Pt}_{5}\right)$ and second cell with a thicker cathode layer $(20 \mu \mathrm{m})$, measured successively with a gold grid and gold paste (cathodes: $\mathrm{CC} 800_{20}$ and $\mathrm{CC} 800 \mathrm{Au}_{20}$ ). A detailed com- parison is performed on the CNLS-fits of the impedance data collected at $700{ }^{\circ} \mathrm{C}$.

Using ZView, the fit procedure considers the whole data set and leads to the following series circuit: $R_{1} L_{1} W_{\mathrm{s}}\left(R_{2} / /\right.$ $\left.C P E_{1}\right)$ [4] and $R_{1} L_{1} W_{\mathrm{s}}\left(R_{2} / / C P E_{1}\right)\left(R_{3} / / C P E_{2}\right)$. In the case of Pt paste as current collector the contribution $\left(R_{3} / / C P E_{2}\right)$ obtained in the low frequency range is widely increased, compared to Au grid collector. No particular information of the cathode behavior can be extracted. The ZView and CNLS-fit results are provided in Table 3 and Figure 9. One

Table $3 \mathrm{CC} \mathrm{COO}_{5}, \mathrm{CC} \mathrm{COOPt}, \mathrm{CC}_{5} \mathrm{CO}_{20}$, and $\mathrm{CC} 800 \mathrm{Au}_{20}$ : fitted circuit elements using ZView 3.3a software.

\begin{tabular}{|c|c|c|c|c|c|c|c|}
\hline \multicolumn{8}{|c|}{ Fit results $700{ }^{\circ} \mathrm{C}-\mathrm{ZView} 3.3 \mathrm{a}$} \\
\hline & \multicolumn{2}{|c|}{$\mathrm{CC} 800_{5}[5]$ and this work } & \multirow{2}{*}{$\begin{array}{l}{\mathrm{CC} 800 \mathrm{Pt}_{5}}_{\text {[5] }} \\
3.06 \Omega(0.6 \%)\end{array}$} & \multicolumn{2}{|c|}{$\mathrm{CC} 800_{20}$} & \multicolumn{2}{|c|}{$\mathrm{CC} 800 \mathrm{Au}_{20}$} \\
\hline$R_{1}$ & $5.3 \Omega(0.08 \%)$ & $5.3 \Omega(0.05 \%)$ & & $4.2 \Omega(0.2 \%)$ & $4.2 \Omega(0.3 \%)$ & $2.8 \Omega(0.3 \%)$ & $2.8(0.3 \%)$ \\
\hline$L_{1}$ & $\begin{array}{l}6.5 \times 10^{-7} \\
\text { Henri }(0.2 \%)\end{array}$ & $\begin{array}{l}6.5 \times 10^{-6} \\
\text { Henri }(0.06 \%)\end{array}$ & $\begin{array}{l}5.9 \times 10^{-7} \\
\text { Henri }(0.8 \%)\end{array}$ & $\begin{array}{l}1.5 \times 10^{-6} \\
\text { Henri }(0.4 \%)\end{array}$ & $\begin{array}{l}1.5 \times 10^{-6} \\
\text { Henri }(0.4 \%)\end{array}$ & $\begin{array}{l}1.6 \times 10^{-6} \\
\text { Henri }(0.4 \%)\end{array}$ & $\begin{array}{l}1.6 \times 10^{-6} \\
\text { Henri }(0.4 \%)\end{array}$ \\
\hline WR & $3.31 \mathrm{c}(3 \%)$ & $4.7(1.5 \%)$ & $1.9(25 \%)$ & $1.3(8 \%)$ & $0.97(69 \%)$ & $0.9(50 \%)$ & $0.9(47 \%)$ \\
\hline WT & $0.0052(6 \%)$ & $0.018(9 \%)$ & $1.1 \times 10^{-4}(14 \%)$ & $0.006(24 \%)$ & $0.009(40 \%)$ & $0.003(24 \%)$ & $0.008(35 \%)$ \\
\hline WP & $0.4(0.7 \%)$ & $0.33(0.5 \%)$ & $0.42(6 \%)$ & $0.3(2 \%)$ & $0.3(20 \%)$ & $0.3(2 \%)$ & $0.3(14 \%)$ \\
\hline $\mathrm{R} 2$ & $2.67 \Omega(4 \%)$ & $0.68 \Omega(15 \%)$ & $6.3 \Omega(11 \%)$ & $0.4 \Omega(28 \%)$ & $0.22 \Omega(72 \%)$ & $0.6 \Omega(14 \%)$ & $0.4 \Omega(40 \%)$ \\
\hline $\mathrm{CPE}_{1}-T$ & $0.017(5 \%)$ & $0.064(9 \%)$ & $0.0074(10 \%)$ & $0.01(15 \%)$ & $0.19(55 \%)$ & $0.06(7 \%)$ & $0.1(31 \%)$ \\
\hline $\mathrm{CPE}_{1}-\mathrm{P}$ & $0.73(2 \%)$ & $0.96(3 \%)$ & $0.48(8 \%)$ & $0.7(6 \%)$ & $0.85(12 \%)$ & $0.8(4 \%)$ & $0.8(7 \%)$ \\
\hline$R_{3}$ & & $0.49 \Omega(18 \%)$ & $5.6 \Omega(6 \%)$ & & $0.38 \Omega(130 \%)$ & & $0.35 \Omega(80 \%)$ \\
\hline $\mathrm{CPE}_{2}-\mathrm{T}$ & & $0.006(19 \%)$ & $0.103(5 \%)$ & & $0.03(83 \%)$ & & $0.02(60 \%)$ \\
\hline $\mathrm{CPE}_{2}-\mathrm{P}$ & & $0.75(5 \%)$ & $0.830(3 \%)$ & & $0.5(32 \%)$ & & $0.5(20 \%)$ \\
\hline$\chi^{2}$ & $4.3 \times 10^{-5}$ & $7.3 \times 10^{-6}$ & $2 \times 10^{-4}$ & $4.8 \times 10^{-5}$ & $2.5 \times 10^{-5}$ & $1 \times 10^{-4}$ & $3 \times 10^{-5}$ \\
\hline
\end{tabular}
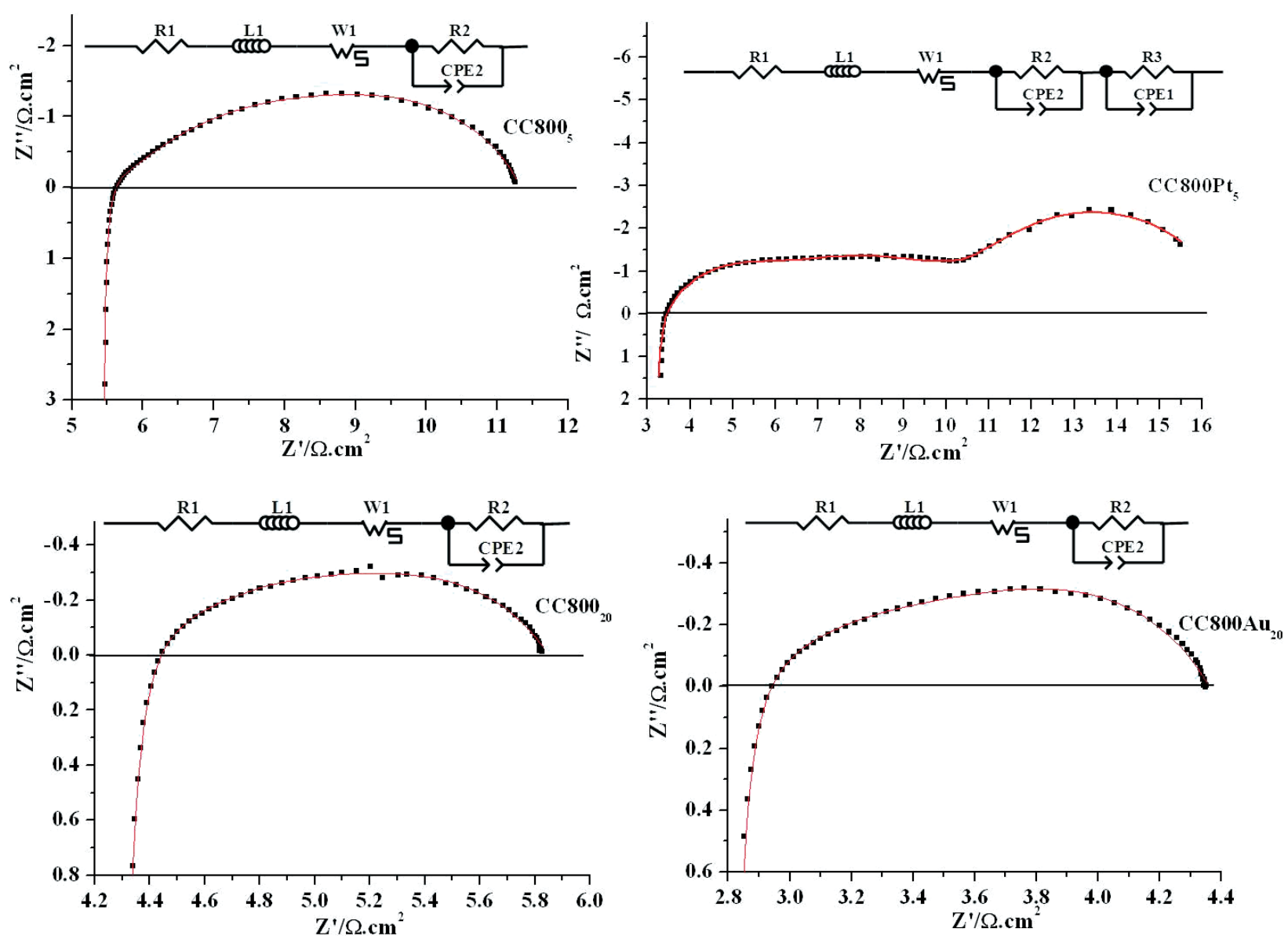

Fig. 9 Experimental impedance plots and the corresponding fits using ZView $3.3 \mathrm{a}$ for $\mathrm{CC}_{200}, \mathrm{CC} 800 \mathrm{Pt}_{5}, \mathrm{CC} 800_{20}$, and $\mathrm{CC} 800 \mathrm{Au}_{20}$. 
must notice, in case of cells measured with the gold paste or gold grid as current collector, that the last part of the circuit $\left(R_{3} / / C P E_{2}\right)$ is not necessarily justified, the associated errors being high for a slightly improved $R_{\mathrm{p}}$ value. The equivalent circuit evidenced in ZView is in good agreement with the circuits reported in refs. [4,5] for the pure and composite compounds.

For the subtraction procedure, the quality of the data is first checked using the KK test. The data are of quite good quality, except for $\mathrm{CC} 800 \mathrm{Pt}_{5}$, where a larger noise contribution is observed in the low frequency region. The KK-test residuals and CNLS-fit results are presented in Figures S7 and S8 of the Supplementary Data Section. The circuits extracted pre- viously on the pure compound, measured with a gold grid as current collectors, were applied to the composite compounds studied in this part. For a better comparison with ZView fits, the series equivalent circuit will be considered, as it is equal to the other one with respect to the fit quality. The series equivalent circuit $L_{1} R_{1}\left(R_{2} Q_{1}\right)\left(R_{3} Q_{2}\right)\left(R_{4} Q_{3}\right)\left(R_{5} Q_{4}\right)$ describes properly $\mathrm{CC} 800_{5}, \mathrm{CC} 800_{20}$, and $\mathrm{CC} 800 \mathrm{Au}_{20}$. One can notice that the same circuit can be used for $\mathrm{CC} 800 \mathrm{Pt}_{5}$. The fit results are presented in Table 4 and the corresponding CNLS-fits compared to the experimental data in Figure 10. The first point to notice is that the pure and the composite compounds show the same behavior, as evidenced by the same equivalent circuits. This means that the same physical phenomena are

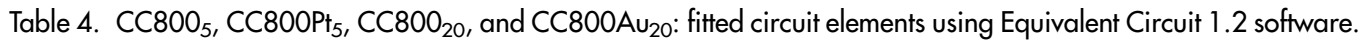

\begin{tabular}{|c|c|c|c|}
\hline $\mathrm{CC} 800_{5}$ & $\mathrm{CC} 800 \mathrm{Pt}_{5}$ & $\mathrm{CC} 800_{20}$ & $\mathrm{CC} 800 \mathrm{Au}_{20}$ \\
\hline$t=714^{\circ} \mathrm{C}$ & $t=701{ }^{\circ} \mathrm{C}$ & $t=701{ }^{\circ} \mathrm{C}$ & $t=702{ }^{\circ} \mathrm{C}$ \\
\hline$L_{1} R_{1}\left(R_{2} Q_{1}\right)\left(R_{3} Q_{2}\right)\left(R_{4} Q_{3}\right)\left(R_{5} Q_{4}\right)$ & $L_{1} R_{1}\left(R_{2} Q_{1}\right)\left(R_{3} Q_{2}\right)\left(R_{4} Q_{3}\right)\left(R_{5} Q_{4}\right)$ & $L_{1} R_{1}\left(R_{2} Q_{1}\right)\left(R_{3} Q_{2}\right)\left(R_{4} Q_{3}\right)\left(R_{5} Q_{4}\right)$ & $L_{1} R_{1}\left(R_{2} Q_{1}\right)\left(R_{3} Q_{2}\right)\left(R_{4} Q_{3}\right)\left(R_{5} Q_{4}\right)$ \\
\hline$L_{1}=6.5 \times 10^{-7}$ Henri $(0.1 \%)$ & $L_{1}=5.6 \times 10^{-7}$ Henri $(0.8 \%)$ & $L_{1}=1.5 \times 10^{-6}$ Henri $(0.9 \%)$ & $L_{1}=1.6 \times 10^{-6}$ Henri $(0.4 \%)$ \\
\hline$R_{1}=5.4 \Omega(0.2 \%)$ & $R_{1}=3.2 \Omega(0.7 \%)$ & $R_{1}=4.3 \Omega(0.6 \%)$ & $R_{1}=2.8 \Omega(0.8 \%)$ \\
\hline$R_{2}=2.2 \Omega(80.3 \%)$ & $R_{2}=1.9 \Omega(79 \%)$ & $R_{2}=5.9 \times 10^{-1} \Omega(101.4 \%)$ & $R_{2}=5.1 \times 10^{-1} \Omega(137.4 \%)$ \\
\hline$Q_{1}-Y_{0}=1.0 \times 10^{-2}$ mho $(25.9 \%)$ & $Q_{1}-Y_{0}=2.9 \times 10^{-4}$ mho $(29.8 \%)$ & $Q_{1}-Y_{0}=1.4 \times 10^{-2}$ mho $(105.1 \%)$ & $Q_{1}-Y_{0}=1.7 \times 10^{-2} \operatorname{mho}(61.8 \%)$ \\
\hline$Q_{1}-n=7.7 \times 10^{-1}(16.0 \%)$ & $Q_{1}-n=7.2 \times 10^{-1}(11.3 \%)$ & $Q_{1}-n=5.8 \times 10^{-1}(32.7 \%)$ & $Q_{1}-n=6.6 \times 10^{-1}(31.3 \%)$ \\
\hline$R_{3}=0.7 \Omega(70.1 \%)$ & $R_{3}=3.0 \Omega(85.4 \%)$ & $R_{3}=2.6 \times 10^{-1} \Omega(64.0 \%)$ & $R_{3}=2.2 \times 10^{-1} \Omega(71.3 \%)$ \\
\hline$Q_{2}-Y_{0}=1.8 \times 10^{-2}$ mho $(30.1 \%)$ & $Q_{2}-Y_{0}=2.3 \times 10^{-3}$ mho $(50.2 \%)$ & $Q_{2}-Y_{0}=2.0 \times 10^{-1}$ mho $(59.4 \%)$ & $Q_{2}-Y_{0}=2.1 \times 10^{-1}$ mho $(67.7 \%)$ \\
\hline$Q_{2}-n=4.3 \times 10^{-1}(7.4 \%)$ & $Q_{2}-n=6.3 \times 10^{-1}(29.5 \%)$ & $Q_{2}-n=8.4 \times 10^{-1}(10.3 \%)$ & $Q_{2}-n=9.0 \times 10^{-1}(8.3 \%)$ \\
\hline$R_{4}=2.2 \Omega(82.0 \%)$ & $R_{4}=2.6 \Omega(42.5 \%)$ & $R_{4}=5.6 \times 10^{-1} \Omega(100.5 \%)$ & $R_{4}=4.7 \times 10^{-1} \Omega(122.7 \%)$ \\
\hline$Q_{3}-Y_{0}=6.2 \times 10^{-3}$ mho $(20.8 \%)$ & $Q_{3}-Y_{0}=1.1 \times 10^{-2}$ mho $(29.7 \%)$ & $Q_{3}-Y_{0}=2.5 \times 10^{-1}$ mho $(39.9 \%)$ & $Q_{3}-Y_{0}=3.3 \times 10^{-2}$ mho $(31.3 \%)$ \\
\hline$Q_{3}-n=6.2 \times 10^{-1}(14.3 \%)$ & $Q_{3}-n=7.1 \times 10^{-1}(8.6 \%)$ & $Q_{3}-n=7.4 \times 10^{-1}(24.5 \%)$ & $Q_{3}-n=8.0 \times 10^{-1}(25.8 \%)$ \\
\hline$R_{5}=7.8 \times 10^{-1} \Omega(42.1 \%)$ & $R_{5}=5.9 \Omega(2.0 \%)$ & $R_{5}=1.3 \times 10^{-1} \Omega(145.2 \%)$ & $R_{5}=4.0 \times 10^{-1} \Omega(77.7 \%)$ \\
\hline$Q_{4}-Y_{0}=6.8 \times 10^{-2}$ mho $(36.5 \%)$ & $Q_{4}-Y_{0}=9.4 \times 10^{-2}$ mho $(2.1 \%)$ & $Q_{4}-Y_{0}=2.3 \times 10^{-3}$ mho $(237.3 \%)$ & $Q_{4}-Y_{0}=1.5 \times 10^{-2}$ mho $(88.8 \%)$ \\
\hline$Q_{4}-n=9.4 \times 10^{-1}(5.7 \%)$ & $Q_{4}-n=8.3 \times 10^{-1}(1.1 \%)$ & $Q_{4}-n=6.8 \times 10^{-1}(40.9 \%)$ & $Q_{4}-n=4.9 \times 10^{-1}(19.2 \%)$ \\
\hline$\chi^{2}=2.5 \times 10^{-7}$ & $\chi^{2}=3.7 \times 10^{-6}$ & $\chi^{2}=6.1 \times 10^{-7}$ & $\chi^{2}=2.7 \times 10^{-7}$ \\
\hline
\end{tabular}

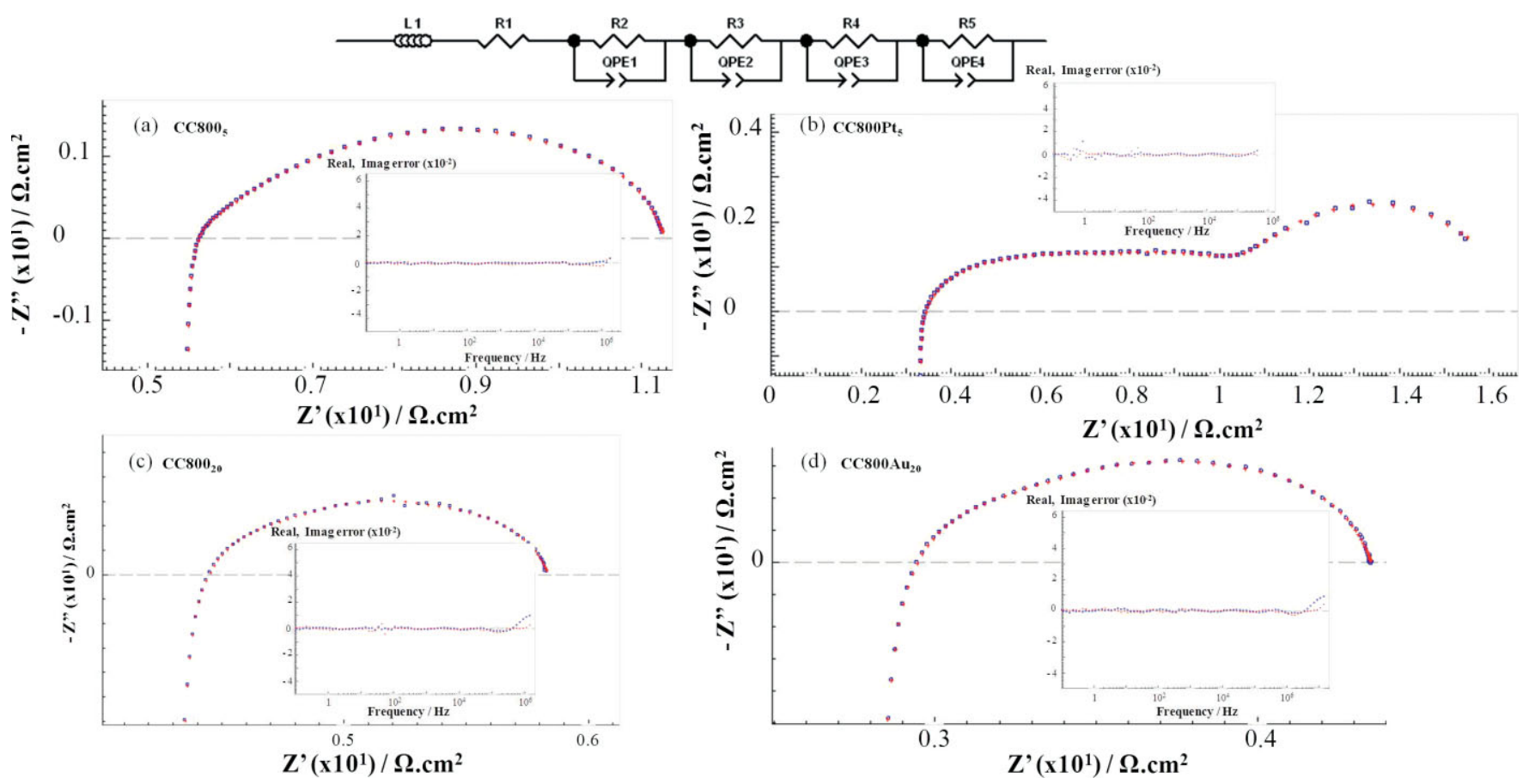

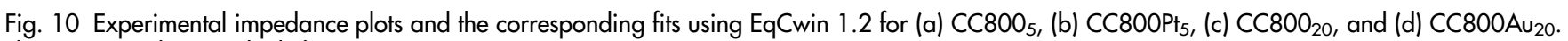
The corresponding residual plots are in insert. 
involved independently of the composition of the cathode: pure Ca349 or composite 70 wt.\% Ca349-30 wt.\% CGO.

In the following sections, the focus is on the subtraction procedures using EqCwin, considering the series equivalent circuit. Some large errors can be noticed. But they are just a consequence of the cross-correlation between parameters. From a general point of view, the errors in the ZView fit appear to be lower, but this is due to the systematic deviation in the residual plots. Knowing that, a correlation between the circuit contributions and physical phenomena has been suggested.

\section{Behavior of $\mathrm{CC} 800_{5}$ Versus CC800Pt}

As presented above, a comparison of the same CC800 cathodes, either with gold grid or with platinum paste current collectors, reveals that two different equivalent circuits: a series and a parallel circuit, could be considered.

As frequency decreases, the resistances appear in the order: $R_{1}, R_{3}, R_{4}, R_{2}$, and $R_{5}$. The resistance parallel to a capacitor chosen to describe the low frequency contribution is related to surface phenomena associated either with the platinum paste or the degradation phases. The high and medium frequency semicircles correspond to the electrochemical behavior associated with the combination of Ca349 and the degradation phases, which constitutes a new cathode. This changed cathode composition leads to quite different electrochemical properties. One can notice that $R_{1}, R_{2}$, and $R_{4}$ are of the same order of magnitude, whereas, using platinum paste as current collector leads to an increase of $R_{3}$ and $R_{5}$.

\section{Behavior of $\mathrm{CC} 800_{20}$ Versus $\mathrm{CC} 800 \mathrm{Au}_{20}$}

$\mathrm{CC} 800_{20}$ and $\mathrm{CC} 800 \mathrm{Au}_{20}$ cathodes responses are both described by a series equivalent circuit. The characteristic resistances appear, with decreasing frequency, in the order $R_{1}, R_{3}, R_{4}, R_{2}$, and $R_{5}$. Special attention paid to the fitted values of the circuit elements (Table 4) reveals that the same order of magnitude is observed for both cathodes. This confirms that the same electrochemical reaction applies when using gold paste or gold grid current collectors.

\section{Behavior of $\mathrm{CC} 800_{5}$ Versus $\mathrm{CC} 800_{20}$}

These two samples differ in their layer thickness. CC800 and $\mathrm{CC} 800_{20}$ have, respectively, a thickness of 5 and $20 \mu \mathrm{m}$. Assuming that each contribution in the equivalent circuit can be associated with different steps in the overall electrochemical cathode reaction, one could assign $R_{3}$ and $R_{4}$ to diffusion phenomena in the cathode layer according to their frequency location on the plot in the $13-10000 \mathrm{~Hz}$ range, approximately, corresponding to the " $\mathrm{C}$ arc" mentioned in the ref. [16]. Similarly $R_{5}$ can be assigned to surface phenomena and $R_{2}$ to the electrode-electrolyte interface impedance. For both samples, the $R_{5}$ values and associated time constants are of the same order of magnitude. For $R_{2}$, differences are evidenced for $\mathrm{R}$ values, but the associated time constants are similar. For $R_{3}$ and $R_{4}$, differences are noticed for $\mathrm{R}$ values and time constant. It seems to indicate that the surface and interface phenomena are not affected by the thickness effect. However, the diffusion phenomenon is affected by the thickness effect. The same physical phenomenon is involved and the thickness affects highly the resistances values. The thick layer shows the lowest polarization resistance. This indicates the importance of the mixed conduction properties of the material and the increased triple phase boundary length which is essential for the oxygen reduction reaction.

\section{Conclusion}

$\mathrm{Ca}_{3} \mathrm{Co}_{4} \mathrm{O}_{9-\delta}(\mathrm{Ca} 349)$ is a mixed ionic, electronic conductor with interesting electrochemical properties, which makes it a good candidate cathode for application in a SOFC. Continued investigations are underway to improve the properties and to understand the electrochemical behavior of this material. Complex mechanisms are involved at the cathode which are much more complicated in case of the composite cathode/ electrolyte. EIS is a key technique to describe the cathode behavior. However, special attention should be paid to the choice of the current collector, which depends on the composition under study. This study, focused on Ca349, revealed that in this case the best current collector is a gold grid. The commonly used platinum paste or grid is here inappropriate as current collector for the SOFC cathode. Reactions between $\mathrm{Ca} 349$ and platinum lead to the formation of several undesirable phases: $\mathrm{CaPt}_{2} \mathrm{O}_{4}, \mathrm{Ca}_{4} \mathrm{PtO}_{6}, \mathrm{Ca}_{3} \mathrm{Co}_{2} \mathrm{O}_{6}$, and $\mathrm{Co}_{3} \mathrm{O}_{4}$. With platinum paste as current collector, the electrode impedance clearly shows two contributions, whereas, with a gold grid current collector only one contribution is observed. Two fit procedures, ZView 3.3a and EqCwin v1.2 were applied for the impedance data analysis. The subtraction procedure provided in EqCwin yields more detailed information on the equivalent circuits than ZView. The CNLS-analysis has made it possible to study the effect of current collector and layer thickness, as part of the study of electrode materials. To confirm the correlation between the circuit elements and the physical phenomena, further electrochemical studies considering various electrode compositions and microstructural properties will be performed under various conditions (temperature, atmosphere, and current). A perspective of the work could be also to describe the actual electrode structure with finite element modeling, as reported by Kornely et al. [17].

\section{Acknowledgements}

The PHC Alliance exchange programme is acknowledged for funding the collaboration with Prof. Irvine's group, at the University of St Andrews. We thank the group for performing screen-printing depositions. K. Nagasawa and H. Nakatsugawa are thanked for initiating the work on the Ca349 material. Nicolas Preux is acknowledged for the results on $\mathrm{Ca}_{3} \mathrm{Co}_{2} \mathrm{O}_{6}$, which are part of his $\mathrm{PhD}$. 


\section{Supplementary Data Section}

Ca349 and LSCF refer to $\mathrm{Ca}_{3} \mathrm{Co}_{4} \mathrm{O}_{9+8}$ and $\mathrm{La}_{0.6} \mathrm{Sr}_{0.4} \mathrm{Co}_{0.8} \mathrm{Fe}_{0.2} \mathrm{O}_{3}$, respectively. EIS refer to electrochemical impedance spectroscopy.

S1 Legend of the abbreviations considered.

\begin{tabular}{|c|c|c|c|c|c|c|}
\hline Composition & Treatment $t /{ }^{\circ} \mathrm{C}$ & Support & Current collector & Thickness / $\mu \mathrm{m}$ & Name & Reference \\
\hline Pure $\mathrm{Ca}_{3} \mathrm{Co}_{4} \mathrm{O}_{9+\delta}$ & $700^{\circ} \mathrm{C}$ & Dense CGO & Au grid & $\sim 40$ & $\mathrm{PC}^{\mathrm{P}} 0_{40}$ & [4] \\
\hline $\begin{array}{l}\text { Composite } 70 \text { wt. } \% \\
\mathrm{Ca}_{3} \mathrm{Co}_{4} \mathrm{O}_{9+\delta}-30 \text { wt. } \% \text { CGO }\end{array}$ & $700{ }^{\circ} \mathrm{C}$ & Dense CGO & Au grid & $\sim 15$ & $\mathrm{CC} 700_{15}$ & [4] \\
\hline $\begin{array}{l}\text { Pure } \mathrm{Ca}_{3} \mathrm{Co}_{4} \mathrm{O}_{9+\delta}+20 \text { wt. } \% \\
\text { cellulose }\end{array}$ & $800{ }^{\circ} \mathrm{C}$ & Dense CGO & Au grid & $5-10$ & PC $800 c_{10}$ & [5] \\
\hline $\begin{array}{l}\text { Pure } \mathrm{Ca}_{3} \mathrm{Co}_{4} \mathrm{O}_{9+\delta}+20 \text { wt. } \% \\
\text { cellulose }\end{array}$ & $900{ }^{\circ} \mathrm{C}$ & Dense CGO & Pt paste & $\sim 10$ & $\mathrm{PC} 900 \mathrm{cPt}_{10}$ & [5] \\
\hline $\begin{array}{l}\text { Composite } 70 \text { wt. } \% \\
\mathrm{Ca}_{3} \mathrm{Co}_{4} \mathrm{O}_{9+\delta}-30 \text { wt. } \% \text { CGO }\end{array}$ & $800{ }^{\circ} \mathrm{C}$ & Dense CGO & Au grid & $\sim 5$ & $\mathrm{CC} 800_{5}$ & [5] \\
\hline $\begin{array}{l}\text { Composite } 70 \text { wt. } \% \\
\mathrm{Ca}_{3} \mathrm{Co}_{4} \mathrm{O}_{9+\delta}-30 \text { wt. } \% \text { CGO }\end{array}$ & $800^{\circ} \mathrm{C}$ & Dense CGO & Pt paste & $\sim 5$ & $\mathrm{CC} 800 \mathrm{Pt}_{5}$ & [5] \\
\hline $\begin{array}{l}\text { Composite } 70 \text { wt. } \% \\
\mathrm{Ca}_{3} \mathrm{Co}_{4} \mathrm{O}_{9+\delta}-30 \text { wt. } \% \text { CGO }\end{array}$ & $800{ }^{\circ} \mathrm{C}$ & Dense CGO & Au grid & $\sim 20$ & $\mathrm{CC} 80 \mathrm{O}_{20}$ & [5] \\
\hline $\begin{array}{l}\text { Composite } 70 \text { wt. } \% \\
\mathrm{Ca}_{3} \mathrm{Co}_{4} \mathrm{O}_{9+\delta}-30 \text { wt. } \% \text { CGO }\end{array}$ & $800{ }^{\circ} \mathrm{C}$ & Dense CGO & Au paste & $\sim 20$ & $\mathrm{CC} 800 \mathrm{Au}_{20}$ & This work \\
\hline $\begin{array}{l}\text { Composite } 70 \text { wt. } \% \\
\mathrm{Ca}_{3} \mathrm{Co}_{4} \mathrm{O}_{9+\delta}-30 \text { wt.\% CGO }\end{array}$ & $700{ }^{\circ} \mathrm{C}$ & Dense CGO & Pt grid & $\sim 20$ & $\mathrm{CC} 700_{20}$ & This work \\
\hline
\end{tabular}

S2 Cell characteristics.

$R_{1} / / C P E_{1}:$

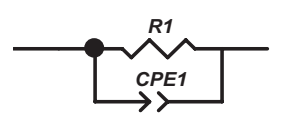

$L_{1} R_{1}\left(R_{2} Q_{1}\right)\left(R_{3} Q_{2}\right)\left(R_{4} Q_{3}\right)\left(R_{5} Q_{4}\right):$

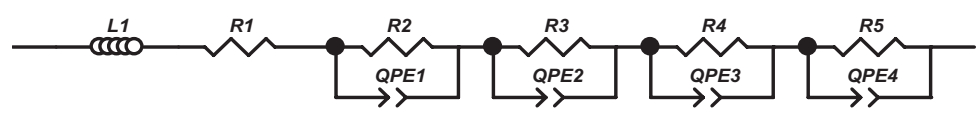

$L_{1} R_{1}\left(Q_{1}\left[R_{2}\left(R_{3} Q_{2}\right)\left(R_{4} Q_{3}\right)\left(R_{5} Q_{4}\right]\right):\right.$

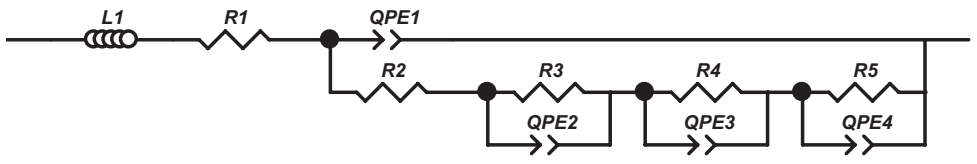

S3 Equivalent circuits symbols. 


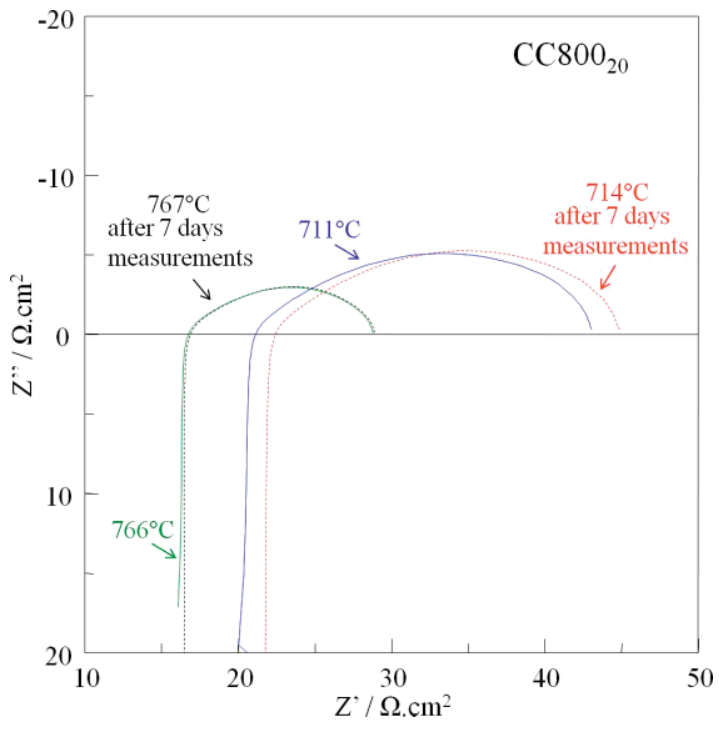

S4 Evolution of gold grid cell CC800Au $\mathrm{u}_{20}$, before and after 7 days measurements.

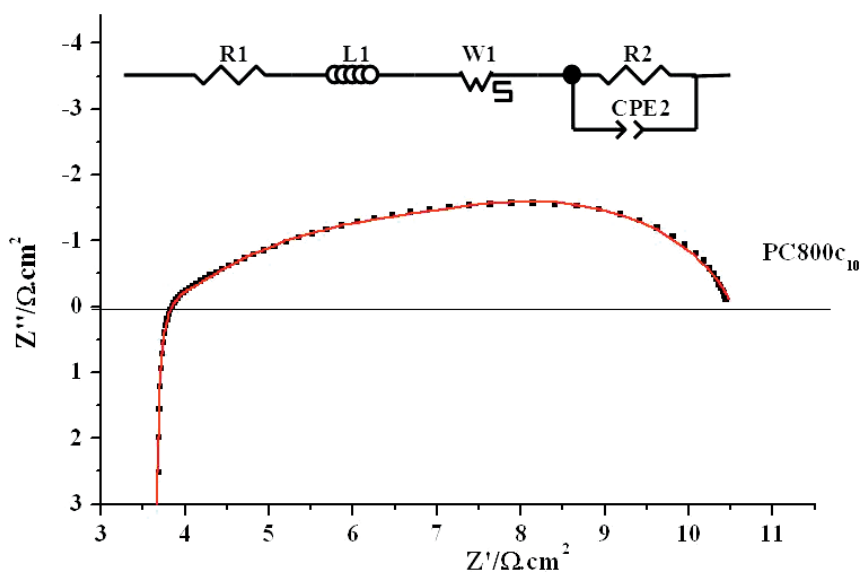

S5 Comparison of the experimental and fitted impedance plots of $\mathrm{PC} 800 \mathrm{c}_{10}$ using ZView 3.3a sofware. Fit are represented in red line and impedance data in black square.
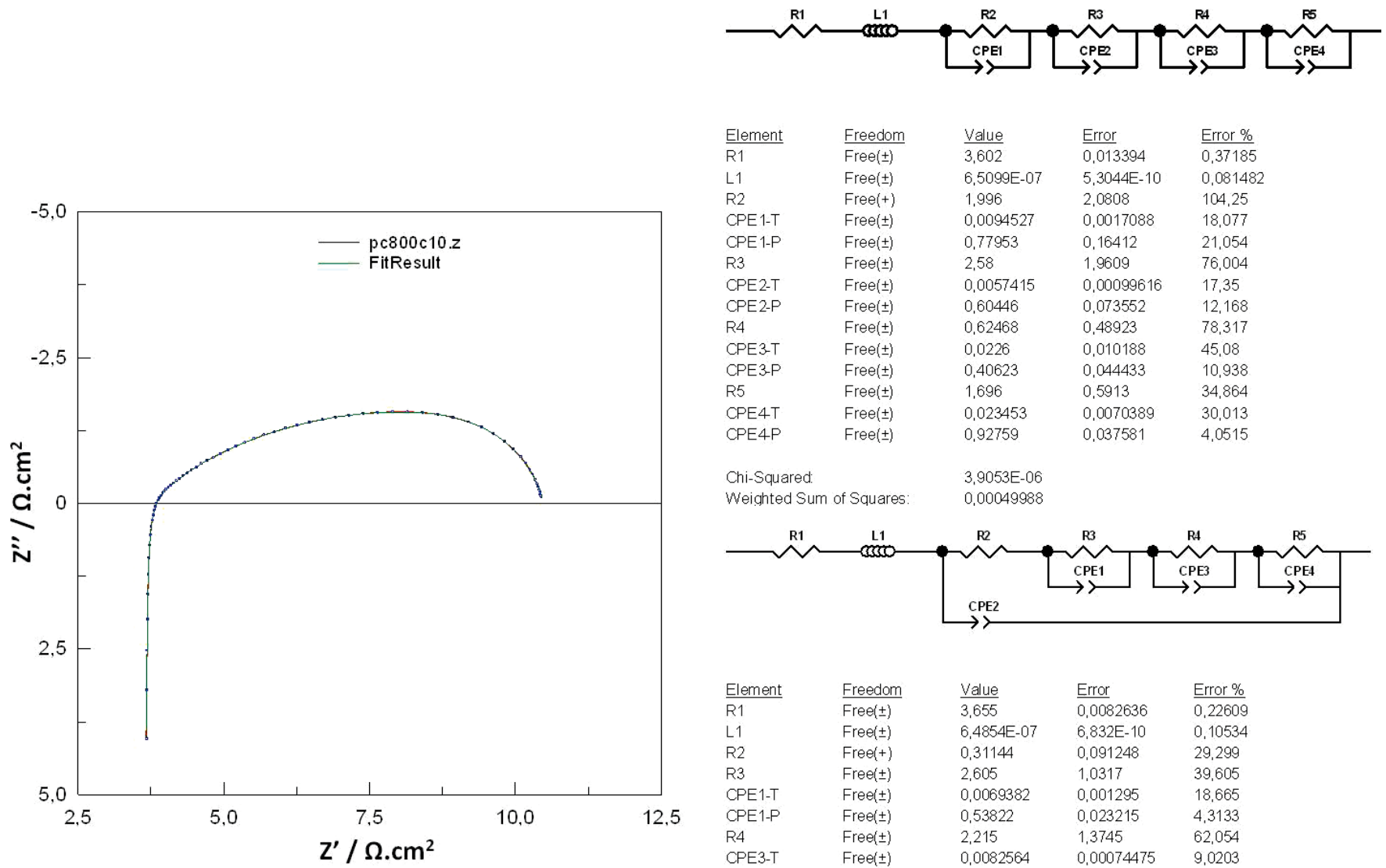

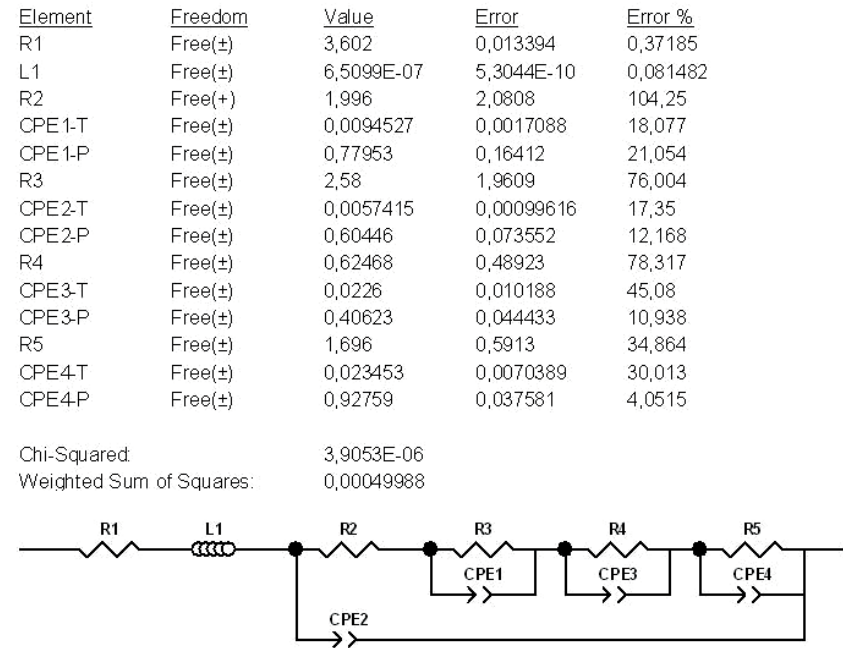

\begin{tabular}{|c|c|c|c|c|}
\hline Element & Freedom & Value & Error & Error \% \\
\hline R1 & Free( \pm ) & 3,655 & 0,0082636 & 0,22609 \\
\hline L1 & Free $( \pm)$ & $6,4854 \mathrm{E}-07$ & $6,832 \mathrm{E}-10$ & 0,10534 \\
\hline R2 & Free(+) & 0,31144 & 0,091248 & 29,299 \\
\hline R3 & Free( \pm$)$ & 2,605 & 1,0317 & 39,605 \\
\hline CPE1-T & Free $( \pm)$ & 0,0069382 & 0,001295 & 18,665 \\
\hline CPE1-P & Free( \pm$)$ & 0,53822 & 0,023215 & 4,3133 \\
\hline R4 & Free( \pm ) & 2,215 & 1,3745 & 62,054 \\
\hline CPE3-T & Free( \pm ) & 0,0082564 & 0,00074475 & 9,0203 \\
\hline CPE3-P & Free $( \pm)$ & 0,744 & 0,10716 & 14,403 \\
\hline R5 & Free $( \pm)$ & 1,724 & 0,44024 & 25,536 \\
\hline CPE4-T & Free $( \pm)$ & 0,021274 & 0,0040123 & 18,86 \\
\hline CPE4-P & Free( \pm$)$ & 0,92839 & 0,03324 & 3,5804 \\
\hline CPE2-T & Free(t) & 0,00021776 & 0,0002262 & 103,88 \\
\hline CPE2-P & Free( \pm ) & 0,7383 & 0,075089 & 10,171 \\
\hline \multirow{2}{*}{\multicolumn{2}{|c|}{ Chi-Square }} & \multirow{2}{*}{\multicolumn{3}{|c|}{$\begin{array}{l}5,953 \mathrm{E}-06 \\
0,00076199\end{array}$}} \\
\hline & & & & \\
\hline
\end{tabular}

S6 Test in ZView of the series and the nested equivalent circuits extracted using EqCwin. 

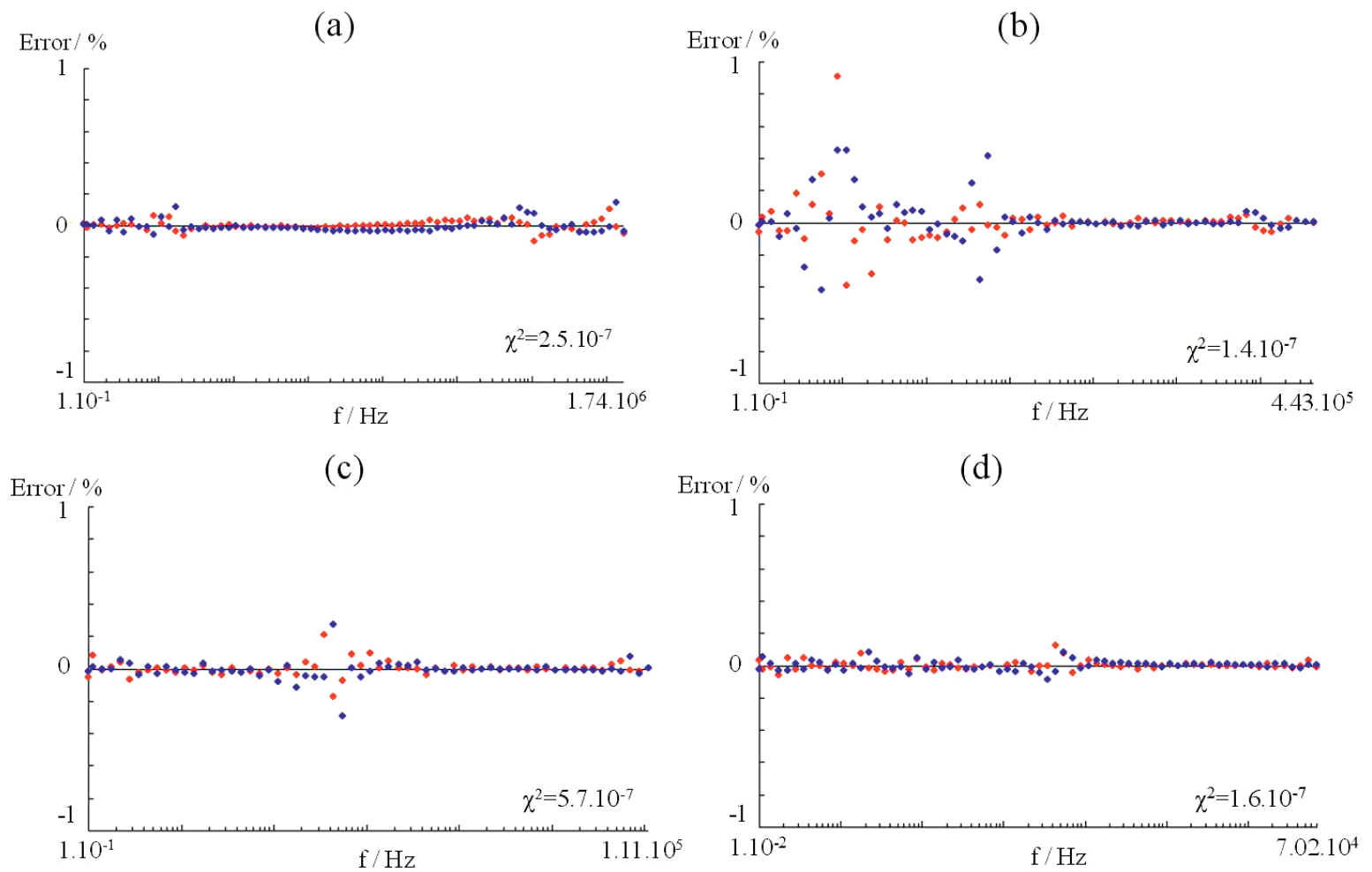

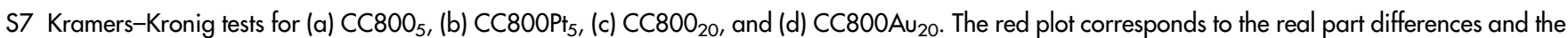
blue plot to the imaginary part differences.

(a)

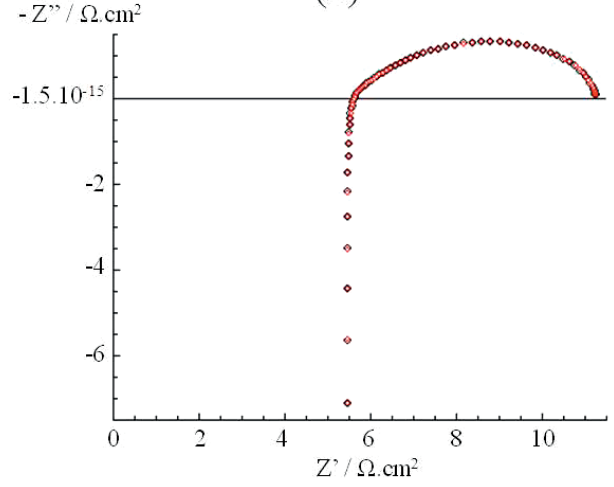

(c)

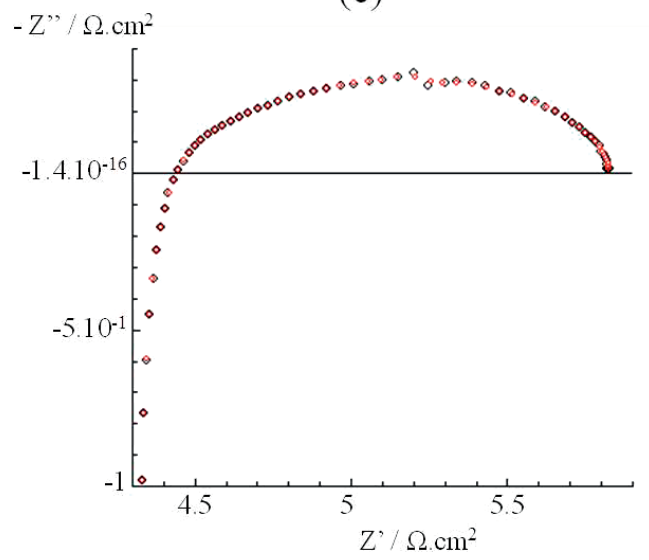

(b)

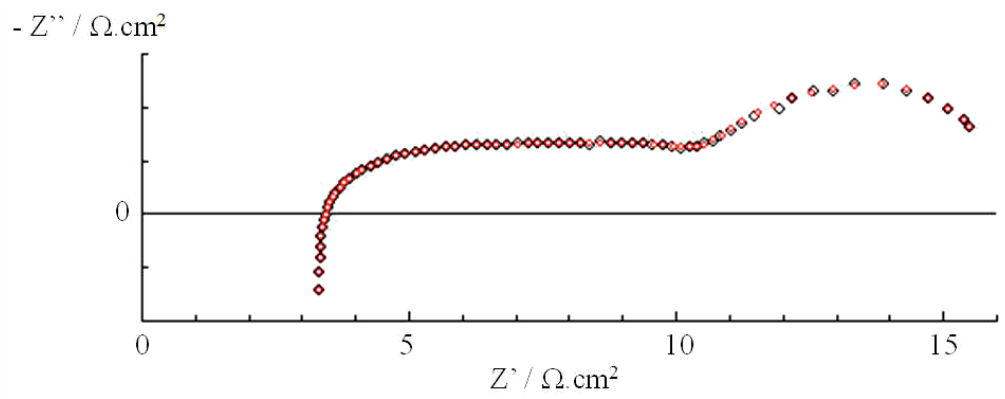

(d)

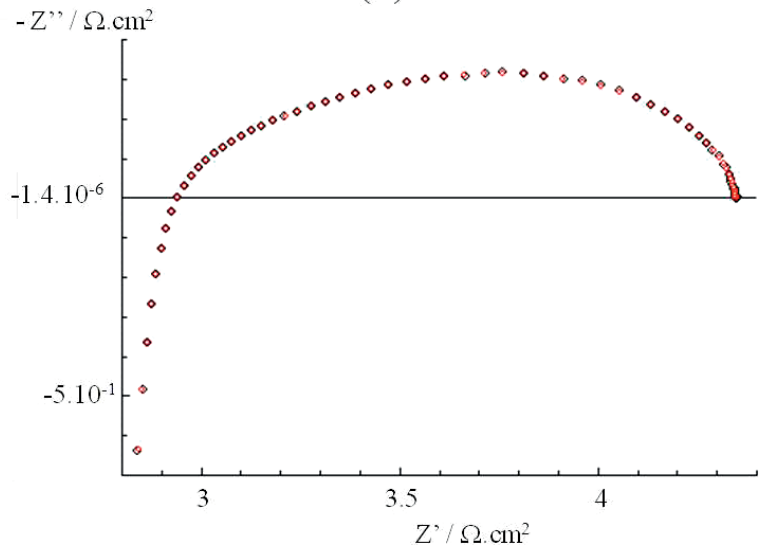

S8 Ideal fits possible to get using the considered data set of (a) $\mathrm{CC}_{300}$, (b) $\mathrm{CC}_{000 \mathrm{Pt}_{5}}$, (c) $\mathrm{CC}_{200}$, and (d) $\mathrm{CC} 800 \mathrm{Au}_{20}$. 


\section{References}

[1] S. B. Adler, Chem. Rev. 2004, 104, 4791.

[2] H. S. Isaacs, L. J. Olmer, E. J. L. Schouler, C. Y. Yang, Solid State Ionics 1981, 3-4, 503.

[3] J. Mizusaki, K. Amano, S. Yamauchi, K. Fueki, Solid State lonics 1987, 22, 313.

[4] K. Nagasawa, S. Daviero-Minaud, N. Preux, A. Rolle, P. Roussel, H. Nakatsugawa, O. Mentré, Chem. Mater. 2009, 21, 4738.

[5] A. Rolle, S. Boulfrad, K. Nagasawa, H. Nakatsugawa, O. Mentré, J. Irvine, S. Daviero-Minaud, J. Power Sources 2011, 196, 7328.

[6] D. Johnson, Z View version 3.3a, copyright 1990-2011, Schribner Associates, Inc.

[7] B. A. Boukamp, Solid State Ionics 1986, 18-19, 136.

[8] B. A. Boukamp, Solid State Ionics 1986, 20, 31.

[9] B. A. Boukamp, Equivalent Circuit (version 1.2), copyright 1985-2009, University of Twente/WisseQ.
[10] E. Capoen, M. C. Steil, G. Nowogrocki, M. Malys, C. Pirovano, A. Löfberg, E. Bordes-Richard, J. C. Boivin, G. Mairesse, R. N. Vannier, Solid State Ionics 2006, 177, 483.

[11] B. A. Boukamp, J. Electrochem. Soc. 1995, 142 (6), 1885.

[12] B. A. Boukamp, Solid State Ionics 2004, 169 (1-4), 65.

[13] Y. H. Lin, C. W. Nan, Y. Liu, J. Li, T. Mizokawa, Z. Shen, J. Am. Ceram. Soc. 2007, 90, 132.

[14] J. Sunarso, S. Baumann, J. M. Serra, W. A. Meulenberg, S. Liu, Y. S. Lin, J. C. Diniz da Costa, J. Membr. Sci. 2008, 320, 13.

[15] N. Preux, PhD, UST - Lille 1, "A la Recherche de Nouveaux Matériaux D'électrolyte et de Cathode Pour SOFC : Weberite et Cobaltite", 2010.

[16] M. J. Jorgensen, M. Mogensen, J. Electrochem. Soc. 2001, 148 (5), A433.

[17] M. Kornely, A. Leonide, A. Weber, E. Ivers-Tiffée, J. Power Sources 2011, 196, 7209. 